\title{
Fonctionnaires au Travail : bureaucratie et personnalité au ministère du Travail dans la période de son cinquantenaire
}

Civil servants at the French Labour Ministry at it's fiftieth Anniversary between Bureaucracy and personality

\section{Pierre Maclouf}

\section{OpenEdition}

Journals

Édition électronique

URL : http://journals.openedition.org/travailemploi/4582

DOI : $10.4000 /$ travailemploi.4582

ISSN : $1775-416 \mathrm{X}$

Éditeur

DARES - Ministère du Travail

Édition imprimée

Date de publication : 30 mars 2007

Pagination : 47-75

ISSN : 0224-4365

Référence électronique

Pierre Maclouf, «Fonctionnaires au Travail : bureaucratie et personnalité au ministère du Travail dans la période de son cinquantenaire », Travail et Emploi [En ligne], 110 | Avril-Juin 2007, mis en ligne le 15 juin 2009, consulté le 01 mai 2019. URL : http://journals.openedition.org/travailemploi/4582 ; DOI : $10.4000 /$ travailemploi.4582 


\title{
Fonctionnaires au Travail: bureaucratie et personnalité au ministère du Travail dans la période de son cinquantenaire
}

\author{
Pierre Maclouf $(*)$
}

\begin{abstract}
Qui sont les hauts fonctionnaires du ministère du Travail dans la période qui va de la Libération aux années 1960 ? Quelles sont leurs carrières et leurs activités quotidiennes, une fois passées les portes du ministère? Rien que de très ordinaire, répond l'auteur: participer à une commission, accueillir un visiteur, présider une réunion, présider - ou être un protagoniste, engagé dans l'affrontement quotidien; s'ils sont conscients d'avoir, parfois, eu une influence, ce sentiment demeure modeste et la gloire est une anomalie. L'auteur ouvre un dialogue, entre la sociologie, l'histoire et la science politique, sur la faisabilité d'une sociologie historique de l'État prenant en compte la personnalité des acteurs et la façon dont ils peuvent référer leurs actes à une éthique du service.
\end{abstract}

«Qu'arrive-t-il à l'aristocratie administrative lorsqu'elle disparaît à l'intérieur de ses forteresses particulières aux environs de dix heures trente, chaque matin en semaine? Que font ses membres? Comment [ses membres] passent-ils les huit heures et demie qui s'écoulent jusqu'à 7 heures du soir ou 7 heures 15,1 'heure à laquelle la plupart d'entre eux s'en vont vers leurs domiciles pour dîner, cinq jours de la semaine?»

Ainsi s'interrogeait, H.E. Dale, ancien directeur général au ministère britannique de l'Agriculture, dans un ouvrage paru en 1941, consacré à la haute fonction publique de Grande-Bretagne (DALE, 1941)(1), fruit non seulement de son expérience personnelle, mais aussi d'une enquête menée auprès de près d'une centaine de hauts fonctionnaires. Cette question trame The Higher Civil Service of Great Britain, ouvrage qui ne connaît pas d'équivalent en France; la seule étude d'ensemble consacrée, dans la période suivant la Seconde Guerre mondiale, par un haut fonctionnaire à la fonction publique, due à R. Grégoire en 1954 (GRÉGOIRE, 1954), relève de la théorie juridique. Le livre de Dale ne se limite pas à une description pénétrante de la vie professionnelle des agents supérieurs de l'administration; il offre aussi une analyse singulière du fonctionnement des ministères, et R. K. Merton, l'un des pionniers américains de la sociologie des organisations, choisit d'en faire figurer un extrait dans le recueil

(*) Université Paris-Dauphine (CERSO). pierre.maclouf@, dauphine.fr

(1) Une recension de cet ouvrage par L.D. White est parue en 1942 dans The American Political Science Review (p. 763765). de textes consacré à la bureaucratie, qu'il publie en 1952 (MERTON, 1952).

Alors que les analyses inspirées de Merton commencent à être reçues en France, notamment sous l'influence de M. Crozier, celui-ci - lui-même également redevable au courant néorationaliste représenté par H.A. Simon dont l'ouvrage fondateur, Administrative Behavior, est paru en 1945 (Simon, 1965) -, entreprend de développer son programme d'étude du phénomène bureaucratique; en 1955 paraît, sous le titre Petits fonctionnaires au travail, un premier jalon d'analyses qui ne tardent pas à se disséminer (CROzIER, 1955). Un ensemble de travaux consacrés au changement dans l'administration donnent matière en 1966, sous l'égide de M. Crozier, à une livraison de la revue Sociologie $d u$ travail (Sociologie du travail, 1966), dont l'un des articles est consacré au «cas d'une administration centrale»: «X», cas d'école de la «résistance au changement», est en fait constitué par le ministère du Travail, dont le cinquantenaire avait été célébré tout juste dix ans plus tôt (LaUtMan, Thenig, 1966). Le plus jeune des ministères, celui du progrès social, serait-il aussi la plus vétuste des administrations?

La réponse au «qu'arrive-t-il ? » d'H. E. Dale peut éclairer ce paradoxe. Cette question, nous l'avons posée à un ensemble de fonctionnaires entrés au ministère du Travail au cours de la période des deux décennies environ encadrant l'époque du cinquantenaire. Les plus anciens d'entre eux sont arrivés au ministère peu avant ou juste après la Libération, le plus jeune en 1968; ils sont allés "au Travail» à la suite d'un concours, et, s'ils sont - comme c'est le cas de la plupart -, anciens élèves de l'ENA, dès leur sortie de l'école. 
Comment passer de l'expérience vécue de (hauts) "fonctionnaires au Travail » à la compréhension du fonctionnement et de l'histoire de cette institution à l'époque considérée? Tel est l'enjeu d'une étude qui suivra un chemin balisé par les métaphores utilisées par R. Grégoire dans son analyse de la notion d' ' emploi» au sein de l'administration: «L'image la plus propre à la matérialiser est celle du fauteuil [...]; le style de ce siège, son confort, varient suivant le genre de travail et l'importance de celui qui l'utilisera; mais sa place n'est pas fixe: il peut être transporté dans plusieurs bureaux devant des tables couvertes de documents très différents, qui, elles, représentent autant de fonctions distinctes » (GRÉGOIRE, 1954, p. 131). On tient là le triangle au sein duquel s'oriente la vie de tout fonctionnaire: la carrière (succession des fauteuils occupés); le poste (la table de travail et l'ensemble des moyens techniques mobilisés), la fonction (le contenu des dossiers qui s'empilent sur la table). L'examen de la relation qu'entretiennent les personnes à chacun des pôles de ce triangle (appréhendée à l'aide d'éléments de la grille conceptuelle avec laquelle H.A. Simon saisit la conduite de l'«homme administratif»), permet d'explorer simultanément les rapports «mertoniens» entre bureaucratie et personnalité (MERTON, 1940) et la question «crozierienne» de la dynamique organisationnelle. Pour comprendre la structure de cette action organisée, et sa relation avec les changements survenus au ministère entre les lendemains immédiats de la Libération et la fin du gaullisme historique incarné par Georges Pompidou, il faut comprendre ce "qui arrive» aux fonctionnaires lorsqu'ils se trouvent «au Travail» (2).

\section{La carrière et la personnalité}

Lorsque, longeant la division 1 en direction du Sud-Est, le visiteur du cimetière du Montparnasse remarque la pierre tombale noire sur laquelle figure le nom d'Olga Raffalovich, médaillée de la Résistance avec rosette, rien ne lui indique quelle fut l'éminence de la défunte au ministère du Travail. De manière parallèle, lorsque l'historien rencontre, au Centre des archives contemporaines, des séries de dossiers rigoureusement classés, destinés à être transmis à sa postérité par la main sûre qui en a systématiquement indiqué le contenu, sans aucune mention personnelle,

(2) Au stade de la rédaction, nous avons pris volontairement le parti de ne pas nommer les locuteurs, ni même de les situer: certains, déjà décédés, avaient fait connaître leur désir de ne pas être cités nommément; d'autres sont toujours vivants et ont préféré demeurer dans la réserve. Nous renvoyons le chercheur au fonds constitué au CHATEFP, qui est à la disposition de tous ( $c f$. l'encadré méthodologique). Les entretiens sont néanmoins référencés en notes dans l'article, en suivant la liste de la «notice introductive» (AO-M 1A, 1B, 2...); les citations d'entretiens (en italique) ont été réduites au strict minimum, et souvent condensées.

\section{Encadré 1}

\section{Un recours à Simon}

Recourir à Simon (SIMON, 1965) dans un travail reposant sur une description compréhensive, n'estce pas là un paradoxe? La postérité du travail de Simon s'est développée sur une ligne formaliste. Son apport peut, néanmoins, être également orienté sur la voie d'une sociologie compréhensive. De même que, contrairement à un schématisme répandu, une critique «cognitive» du fonctionnement interne de la bureaucratie se trouve déjà chez $\mathrm{M}$. Weber, l'œuvre de Simon ne peut être réduite à un néo-rationalisme abstrait.

S'interrogeant ainsi en 1947, dans son avantpropos à Administrative Behavior, sur les implications du livre de Simon pour les hommes d'affaires traitant au jour le jour de situations concrètes, $\mathrm{C}$. Barnard relevait que cet ouvrage se situe au niveau où la similarité de la description des problèmes d'une université et de celle des problèmes d'une organisation militaire débouche sur des formulations à portée générale. On peut alors réduire les incohérences entre les conduites et leur description verbale. Reconstruisant pour sa part, dans son introduction à la deuxième édition de son ouvrage (1957), une conversation imaginaire entre des acteurs organisationnels, et montrant son caractère transposable, Simon invite à mettre en rapport la compréhension de l'environnement expérimenté par chacun avec le cadre théorique qui est le sien (SIMON, 1965, p. XVIIXVIII.), visant à élucider la relation entre les différentes dimensions mentales de la conduite organisationnelle et les structures et formes organisationnelles (ibidem, p. XV ss.).

De cette approche, que nous mettons en tension avec la question «mertonienne» de la personnalité, nous avons principalement retenu, comme instrument formalisé d'abstraction, et en nous en tenant à l'environnement des phénomènes décisionnels - laissant de côté ces derniers - , trois compartiments: la rationalité (associée au traitement de la connaissance), l'autorité (l'obtention de l'acquiescement), l'identification (souvent décrite comme «loyauté » - en fait une incorporation des valeurs de l'organisation, fondatrice de la motivation), correspondant aux chapitres IV, VII et X de l'ouvrage, en les appréhendant autour des effets de cognition et des effets de disposition dans les relations entre organisation et personnalité. C'est d'ailleurs là la matière même du livre de Simon, lequel veut montrer comment ce qui est décrit, par le sens commun, comme la seconde, se forme au sein de la première. Tout en mobilisant, au fil de cette étude, les abstractions permettant d'atteindre le niveau où les problèmes structuraux du ministère du Travail - tels qu'ils sont décrits par ses fonctionnaires -, sont aussi les problèmes d'autres ministères, nous avons insisté, davantage que Simon, sur le phénomène de la personnalité.

Les catégories de l'analyse simonienne de la conduite administrative nous ramènent en effet à «la contribution scientifique peut-être la plus géniale de Weber» (HENNIS, 1996, p. 109): les conséquences pour la conduite de vie qu'entraîne l'exigence d'obéissance à un ordre (Stand, ensemble conventionnel de règles de conduite) : le «sujet [est alors] le résultat de la personnalité » (HENNIS, ibidem). 


\section{Encadré 2 \\ Méthodologie}

Une institution est à la fois une idée directrice et un groupe d'hommes, écrivait R. MousnieR (1974, p. 5). Aussi l'étude présentée s'inspire-t-elle de la recommandation de $\mathrm{M}$. Weber - si souvent revendiquée et si rarement opérationalisée - , selon qui la tâche de la sociologie est de «réduire les concepts généraux tels que l'État, catégories désignant des formes déterminées de coopération humaine, à une activité compréhensible, c'est-à-dire à l'activité des individus participants » (WEBER, 1913, 439).

En 1998-1999, à la demande de la DARES et pour le compte du Comité d'histoire du ministère du Travail (CHATEFP), nous avons réalisé vingt-cinq entretiens approfondis semi-directifs auprès d'une quinzaine de fonctionnaires et anciens fonctionnaires du ministère (1). Le guide d'entretien comprenait les grandes unités suivantes: la formation, la carrière, le service-clé, l'activité personnelle au ministère, l'action du ministère, le système d'action, les autres éléments personnels (origines, idéal de jeunesse...). Les entretiens ont été réalisés, le plus souvent à deux reprises, auprès de fonctionnaires ayant appartenu tant aux services administratifs qu'aux corps de contrôle, aux services centraux (DGTE, Délégation à l'emploi, DPM) qu'aux services extérieurs. L'ensemble du matériel d'enquête est disponible pour la consultation au CHATEFP, accompagné d'une «notice introductive» (MACLOUF, 2006) précisant les problèmes rencontrés (2).

On a introduit ici une méthode de sociologie qualitative, fondée sur l'enquête directe, dans l'analyse d'un objet historique (le Travail dans la «période du cinquantenaire »), rejoignant une perspective suggérée en 1989 par les Annales - appliquée, entre autres, à l'étude des organisations - , en se gardant «de n'être qu'une chambre d'échos des sens donnés à leurs pratiques par les différents acteurs impliqués [...] » (FRIDENSON, 1989, p. 1474), et en se mettant à la recherche, souvent réussie, des traces matérielles de l'activité des personnes interrogées (cf. les «sources» à la fin de cet article) II s'agit de ne pas réduire le discours à une information factuelle, et d'éviter de passer immédiatement de la véridicité de la mémoire à celle de l'événement. La source «fabriquée» (DESCAMPS, 1991 et 2006; MACLOUF, 2006) doit être confrontée à d'autres sources.

(1) Nous remercions très sincèrement chacun d'entre eux pour le temps consenti et pour la confiance qui nous a été accordée.

(2) Nous avons bénéficié, pour une première retranscription, de l'aide précieuse de Madame Liliane Zand, agent de la DARES, que nous remercions vivement, ainsi que ses responsables.
C'est volontairement enfin que nous avons mobilisé une littérature sociologique et juridique datant de la période. Expression de cette dernière, elle demande - s'agissant de travaux devenus classiques - une reconsidération à partir des questions de l'observateur contemporain: elle est à la fois une référence et un objet. Nous nous sommes ainsi appuyé, outre sur Merton, Simon et Grégoire, sur une relecture, à quarante ans de distance et à partir d'un nouveau matériel, des résultats de l'enquête menée en 1964 sur la DGTE par le Groupe de sociologie des organisations, dirigé par M. Crozier (LAUTMAN-THCENIG, 1966).

La mise en relation de ces deux séries de sources (rapportant l'une à l'autre la source « déjà là » et la source “fabriquée») permet d'étayer une histoire d'organisation recourant à une méthode d'entretiens. Si les sources écrites permettent de relativiser les sources orales, ces dernières (à la double condition que le chercheur adopte le point de vue «deutend verstehen » (Weber), et qu'elles soient déjà analysées), agissent - lorsque l'on se transporte de la précision verbale à la rature sur le texte, ou inversement de la date approximative, dans le récit des circonstances, à l'organigramme -, comme contrôle du rapport subjectif aux sources écrites elles-mêmes.

La perspective méthodologique de cette étude qui, au-delà des fonctionnaires du Travail, touche à la fonction publique elle-même, se situe ainsi au carrefour de la sociologie, de l'histoire et de la science politique, et articule la théorie des organisations et une approche institutionnaliste. En se situant sur le plan des rapports internes à l'organisation du «travail », on s'est écarté de la perspective des «politiques publiques » (MÉNY, THCENIG, 1989), laquelle envisage d'abord la relation à l'environnement externe; en introduisant la question institutionnelle et la perspective historique, on s'est éloigné de la théorie dominante des organisations; en projetant dans un objet historique la grille d'H.A. Simon, on s'est mis à distance de l'histoire sociale et politique; mais on a introduit, dans l'histoire du social et dans celle du politique, l'analyse des relations sociales qui sous-tendent l'histoire de l'État, tentant d'aller à la rencontre des attentes, maintes fois formulées depuis 1968 par P. Legendre, et régulièrement déçues, à l'endroit de la sociologie des organisations: «J'attendais, en particulier de la sociologie, qu'elle contribuât à faire reconnaître l'énorme capital d'expériences accumulé par le juridisme français, et je pensais qu'[...] il deviendrait possible [...] d'entrer dans la compréhension du système de l'État en France, avec un peu plus de flexibilité, de finesse [...] entre disciplines appelées à se concerter sur le terrain juridique précisément, leur terrain commun. Las! » (LEGENDRE, 1992, p. 482-483) rien ne lui permet de penser a priori qu'il s'agit là de l'œuvre d'Olga Raffalovich. Si elle précède les responsabilités de sous-directeur des relations professionnelles - auxquelles elle accède à l'âge de 39 ans - , la personnalité de la femme d'action n'émane pas immédiatement des traces léguées par la femme de dossiers, que son envergure conduira aux fonctions de chef du service du Travail, dans lesquelles elle prendra sa retraite, à l'âge de 65 ans, plus de quarante ans après être entrée dans cette administration.
Si l'on met de côté les formes pathologiques - telles le «carriérisme»-auxquelles donne lieu leur interaction, quelles sont les relations normales qui s'établissent entre carrière et personnalité? La première procède des règles bureaucratiques de la sélection et de l'avancement; la seconde exprime une singularité. La carrière est un lieu disposé pour la course; elle est aussi un champ libre. Existence professionnelle continuée dans le temps, elle est alors la résultante d'un agir, d'une volonté, d'at- 
titudes psychosociales, trois éléments personnels qui se projettent dans le déroulement de son cours, dans la détermination de la filière d'appartenance, dans enfin, la disposition de l' "uad-ministrateur» à l'égard du pouvoir politique: qui sont donc les fonctionnaires du Travail?

\section{La carrière, un « libre cours »?}

Alors que le ministère s'apprête à célébrer son cinquantenaire, le déroulement des carrières est encore empreint de la marque de la stabilité administrative héritée de la III ${ }^{\mathrm{e}}$ République (3). Les trois quarts des cadres de 1956 étaient déjà présents avant la Libération, un autre contingent étant arrivé à ce moment-là (4). Bien que le corps en principe unitaire des administrateurs civils ait alors franchi le cap d'une décennie d'existence, les emplois sont encore en grande partie occupés par les fonctionnaires issus du cadre ministériel des rédacteurs, intégrés dans le nouveau corps, ou bien versés dans le cadre spécial des agents supérieurs. La progression de la carrière s'effectue en général au sein de la même sous-direction, voire du même bureau, au sein duquel sont encore franchies les étapes obligées des grades (les rédacteurs étant devenus, en 1946, administrateurs ou agents supérieurs(5)), avant d'accéder aux fonctions de chef de section de bureau, ou de chef de bureau. Une telle progression n'est pas pour autant mécanique - on peut demeurer dans la même position pendant toute une vie professionnelle. Elle laisse place à d'exceptionnelles échappées vers le sommet: le poste de sous-directeur ou, plus rarement encore - ce qui est le cas de Betty Piguet en 1972, alors qu'elle entre dans sa soixantième année, et de Pierre Fournier qui lui succède en 1973, alors qu'il compte déjà trente ans de présence place de Fontenoy (FourNier, 2006, p. 158) - , de chef de service (une règle coutumière plus tardive étant que soit, à partir de 1956, confiée à un «libre coureur» venu d'un corps externe - pas toujours le

(3) De 1944 à 1958, c'est au travail - immédiatement après l'agriculture - que la durée moyenne des fonctions de directeur a été la plus élevée $(5,2$ ans) - la durée moyenne tous ministères confondus ayant été de quatre ans (SIWEK-PouydESSEAU, 1969, p. 73). En fait, et si l'on excepte le cas éphémère (et particulier) de Pierre Juvigny, il n'y a eu que deux directeurs entre 1948 et 1963, et trois de 1948 à 1966. Selon l'enquête de J. Lautman et J.-C. Thœnig, réalisée en 1964, la moyenne d'âge des administrateurs du ministère dépassait alors la cinquantaine (LAUTMAN, Thoenig, 1966, p. 297).

(4) Bottin administratif, Paris, Didot-Bottin. (NB: nous avons systématiquement utilisé les éditions annuelles de 1943 à 1976).

(5) À partir de 1945, la distinction s'effectue entre les «classes» d'administrateur ou d'agent supérieur.
Conseil d'État (6) - la responsabilité de la direction ainsi délivrée des contraintes du système interne).

C'est dans cette dynamique lente - redoublée par le peu d'empressement à leur égard de la puissante Direction du personnel de Fernande Girard - que les premiers administrateurs civils issus de l'ENA - fort rares au long de la première décennie, en plus grand nombre vers la fin de la période -, doivent insérer leur carrière. Au point de célébrer comme un événement l'accès de l'un d'entre eux, le premier à occuper cette responsabilité, aux fonctions de chef de bureau(7). Toutefois, les sortants de l'ENA entrés au ministère à cette époque connaissent des carrières comparables à celles des anciens rédacteurs, encore que puissent leur être confiées plus tôt des responsabilités fonctionnelles (8); les dernières années d'activité de ceux qui sont parvenus à la fonction de sous-directeur peuvent se passer à l'inspection générale.

Alors que la mobilité des cadres anciens est interne (9) et non systématique, la modification des formes de recrutement - effectué à partir de 1945 selon des normes théoriquement interministérielles (10)-s'accompagne de l'introduction, dans l'univers de la stabilité, de la notion antinomique de «mobilité» - voulue par le statut des administrateurs civils -, dans la réalisation de laquelle s'expriment des éléments de choix personnel.

La systématisation de la «mobilité» tend au débordement de son caractère d'obligation: elle devient le principe de trajectoires qui, pour certaines, essai-

(6) Jusqu'à la création de la DGTMO en février 1956, les directeurs respectifs du Travail et de la main-d'œuvre, Édouard Lambert, inspecteur du travail et Alfred Rosier, ancien rédacteur, sont des cadres de la maison. Si les deux premiers directeurs généraux, Pierre Juvigny et Pierre Laurent sont chacun maître des requêtes au Conseil d'État, aucun de leurs trois successeurs de 1963 à 1975 - Jacques Chazelle, Jacques Legrand et Gabriel Oheix - n'est membre de cette assemblée.

(7) Le premier «ancien de l'ENA» (et le plus ancien aussi) à accéder à une responsabilité, Dedieu, a dû patienter de longues années sous l'autorité de madame Grimaud, son chef du $1^{\text {er }}$ bureau à la DGSS, avant de lui succéder dans cette fonction lorsqu'en 1959 elle devient chef de la division des études et de la coordination. L'événement est fêté avec ses collègues sortis de l'ENA: «On a pris le champagne» (AO-M 7A, p. 12 - rappel: ici et ci-après, $\mathrm{AO}-\mathrm{M}=$ archives orales du CHATEFP, Fonds P. Maclouf). À cette époque, la quasi-totalité des emplois de chef de bureau sont encore occupés par la génération d'avant 1945.

(8) Jacques Dupront, de la promotion 1957 de l'ENA, se voit confier dès 1962 la responsabilité d'un secteur à la section des études générales; en 1967, il est chef du bureau des études générales; en 1971, il est - si l'on excepte le cas atypique de Pierre Fournier, entré à l'ENA après neuf ans déjà passés au travail -, le premier ancien élève de cette école à accéder aux fonctions de sous-directeur. Il a déjà près de treize ans de présence au ministère, contre vingt-quatre pour Pierre Fournier, lorsque ce dernier est officiellement nommé sous-directeur en 1967.

(9) Ainsi Renée Petit quitte-t-elle en 1954 la direction du travail pour devenir sous-directeur des accidents du travail à la Sécurité sociale.

(10) C'est la caractéristique du corps des administrateurs civils, qui se distinguent en cela des rédacteurs de ministère. 
ment hors du lieu de l'affectation d'origine, vers les grands organismes sous tutelle (AFPA(11), FAS...), voire le secteur privé - sans parler du départ vers les cabinets ministériels, qui devient par la suite caractéristique du «libre cours»(12), mais est exceptionnel pour les membres de l'ancien cadre (13). La mobilité représente alors un idéal (il est ainsi vu comme une "chance» de "changer tous les sept ans de poste», ou d'avoir exercé six fonctions différentes à chaque fois pendant cinq ans). Si la carrière est une suite de fonctions successives occupées, c'est moins la nature même de celles-ci que les formes de l'enchaînement qui sont importantes: elle est au principe de la mémoire existentielle.

Cette nouvelle mobilité migratoire joue d'ailleurs dans les deux sens : le ministère n'est pas seulement une administration d'où l'on émigre, il est aussi un ministère vers lequel on immigre (c'est non seulement, on l'a vu, le cas des directeurs généraux; c'est aussi celui d'un Claude Thomas, sous-directeur au secrétariat d'État aux Forces armées - marine -, devenu chef du service du FNE en 1964(14) et l'un des auteurs de la différenciation des formes d'action au sein de la DGTE), voire vers lequel on revient (après un détachement à l'AFPA ou un "passage» par le secteur privé).

Ces changements s'effectuent dans le cadre de normes constantes: la carrière demeure liée à des situations de contrainte et de dépendance. Contrainte statutaire: non seulement - même s'il est devenu administrateur civil - , un ancien attaché principal, issu du corps des secrétaires d'administration, connaît une progression moins rapide; mais son accès à son degré d'espérance maximale - chef de bureau ou adjoint à un sous-directeur - est soumis aux bouleversements aléatoires des arrangements prévus: retour rapide d'un chef de bureau malade, mésentente entre aspirants à une promotion conduisant à une nomination imprévue, départ inopiné de l'auteur d'une promesse. Et, fût-il collaborateur direct du directeur général, l'agent contractuel, situé en dehors du statut général, ne représente-t-

(11) Ainsi Gabriel Oheix devient-il secrétaire général de l'AFPA en 1965, puis, en 1971, directeur de cet organisme, et Dominique Balmary y accomplit-il sa mobilité de 1971 à 1974 .

(12) Dominique Balmary est membre du cabinet de Joseph Fontanet en 1969, soit deux ans après sa sortie de l'ENA; Marcel Pochard, chef du bureau du FNE, devient membre du cabinet de Michel Durafour en 1975, soit cinq ans après sa sortie (il était parti en mobilité un an plus tôt dans la préfectorale); il occupe ensuite des fonctions en cabinet jusqu'en 1981.

(13) Ainsi Pierre Demondion, qui entre en 1968 au cabinet du secrétaire d'État chargé de l'Emploi, Pierre Dumas. Ce fonctionnaire (qui a été directeur-adjoint pour l'emploi auprès de Pierre Laurent puis de Jacques Chazelle) était entré au ministère trente ans plus tôt.

(14) Puis, très rapidement, adjoint du directeur général, Jacques Chazelle; tous deux venaient du cabinet du ministre, Gilbert Grandval, mais aucun n'était issu de l'administration du Travail. il pas la figure excentrique de la «mission» définie en dehors de la carrière? L'importance des normes statutaires dans la carrière se manifeste dans des conflits, individuels, liés au refus de prolongation d'un détachement à Bruxelles(15), ou bien collectifs lorsque, en 1965, la section des anciens élèves de l'ENA du ministère (16) met en cause ouvertement la réforme organisationnelle voulue par Jacques Chazelle, la dispersion envisagée des bureaux venant bouleverser les règles d'affectation des responsabilités (17).

Dépendance politique ensuite, pour les emplois de direction, dont la durée suppose la confiance du nouveau ministre - ce qui se traduit a contrario par le départ(18). Plus subtil est le phénomène sur lequel repose le moment déterminant du «cours» de la carrière, lié au repérage subjectif, par le détenteur d'influence, ou de pouvoir politique ou administratif, et par-delà la fonction de l'intéressé, des qualités de la personne appelée; il lui "fait signe»; dans des cas limites, on " vient [la] chercher ». «On $m$ 'a demandé... »: la carrière dépend de la prononciation du nom par autrui. "Être appelé» par le ministre, alors que l'on se trouve dans son bureau, c'est là «une espèce de hasard sans prix».

Résultat partiel de dispositions personnelles, et donc non prévisible d'avance, la carrière est cause d'empreintes successives - autant de moments lors desquels, d'une part s'éprouvent les dispositions fondamentales à l'obéissance ou bien à l'agir libre, et d'autre part s'approfondissent, au contact de l'expérience, les facultés cognitives requises lors de la sélection initiale par le concours. Du premier discours écrit par le stagiaire de l'ENA pour le préfet en vue de l'inauguration d'un lotissement social, à la première note sur la situation de l'emploi à l'attention du directeur du cabinet du ministre, en passant par la succession des dossiers transmis à la série des chefs successifs, la carrière est une accumulation empirique d'expériences à retraduire dans les catégories administratives. De ce qu'il a compris lors de sa mission accomplie en Sarre en 1948, comme conseiller juridique auprès du Haut-commissaire de ce territoire (19), peut être induite la "connaissance $d u$ charbon de Lorraine» et donc des problèmes posés par la «reconversion» des mineurs, que

(15) AO-M 6B: p. 1 à 3.

(16) Animée par Jacques Dupront, alors chef de l'un des deux bureaux issus de la section des études générales.

(17) Arrêté du 16 décembre 1965 relatif à l'organisation de la DGTE.

(18) Ce fut la cas de Jacques Chazelle, en 1966, à qui JeanMarcel Jeanneney, le nouveau ministre des Affaires sociales, refusait la délégation de signature ( $c f$. FourNIER, 2006, p. 144. Voir aussi AO-M 6A, p. 8).

(19) Cette fonction était confiée à Gilbert Grandval. 
rencontre; dix ans plus tard, Pierre Laurent, alors qu'il est directeur de la DGTMO (20).

On remarque que ce sont souvent des moments personnellement significatifs qui - bien qu'étant souvent des intermèdes entre deux périodes - impriment leur marque sur la carrière, lui donnant le sens tenu par le «coureur» comme véridique. Ainsi de l'expérience faite par Gabriel Oheix lorsque, de 1962 à 1965, il est sous-directeur des affaires sociales au secrétariat d'État aux Rapatriés, puis à la direction des Affaires économiques et sociales des rapatriés au ministère de l'Intérieur, années au cours desquelles le contrôleur général de la Sécurité sociale découvre l'action opérationnelle - démarche qu'il suscite plus de dix ans plus tard dans le cadre de la Délégation à l'emploi. Relevons encore ici la figure d'Olga Raffalovich - elle ne devient jamais directeur (21) - , en l'associant à celle de Jane Boy, simple administrateur civil au bureau de la représentation des salariés jusqu'à sa retraite: deux trajectoires égales par leur parallélisme, au-delà même de la carrière et de la vie: la seconde repose au Montparnasse aux côtés de la première; toutes deux ont indiqué, gravée dans la pierre commune, quelle identité (plus forte que le statut, donc clef de compréhension de leur trajectoire) était la leur dans la suite du temps : la Résistance.

Qu'elle soit ascensionnelle ou à l'inverse qu'elle se développe au même niveau hiérarchique, la carrière dépend ainsi de ces "attitudes les plus fondamentales que nous appelons "personnalité"》 (MARCH J., Simon H., 1989, p. 81): elle résulte des dispositions des acteurs. Tel agent supérieur, ancienne de la France libre, très liée à Olga Raffalovich, ne devient jamais chef de bureau, s'en tenant constamment à une deuxième ou troisième position (22), et ne tente jamais de devenir chef-adjoint de bureau - alors que tel secrétaire d'administration aura l'ambition réussie de parvenir à une telle responsabilité.

À partir de 1970, la physionomie du groupe des fonctionnaires change. De la génération entrée au ministère antérieurement à la Libération, il ne reste, lorsque Gabriel Oheix devient directeur général, en mars 1973, que quelques individus (Betty Piguet - à la veille de son départ-, Maurice Chachuat(23),

(20) P. LAURENT, «Les problèmes sociaux posés par la conversion des entreprises», Revue française du travail, $\mathrm{n}^{\circ} 2$, avriljuin 1961 : p. 3-22.

(21) Hormis l'année passée comme chef de cabinet d'Alexandre Parodi, elle n'appartient plus jamais à un cabinet ministériel à partir de sa nomination comme sous-directeur des relations professionnelles en octobre 1945; elle est, depuis le départ de Robert Jaussaud, en 1948, directeur-adjoint, puis chef de service jusqu'à son départ en retraite en 1971.

(22) Au 7e bureau de la Direction du travail de 1945 à 1957 , puis à la section des études générales de 1958 à 1964, enfin, avec Jane Boy, au bureau chargé de la représentation des salariés de 1965 à 1978.

(23) Alors chargé d'un projet de recodification du droit du travail, il décède peu après.
Maurice Meunier(24), le plus jeune étant Pierre Fournier) (25); les anciens élèves de l'ENA sont devenus les plus nombreux. Toutefois, l'opposition de deux modèles de carrière, davantage qu'à une opposition des anciens et des modernes, renvoie à des types contrastés de personnalité organisationnelle.

\section{Les orientations de la «voie sociale»}

«Je suis rentré par choix»; "Très rapidement, je me suis intéressé aux problèmes sociaux». Si personne - quel que soit le niveau atteint - n'évoque un quelconque élément «vocationnel» dans le fait d'être devenu fonctionnaire, le fait d'être fonctionnaire du Travail est toujours, de manière plus ou moins intense, associé à une préférence personnelle «innée » d'une part, à la socialisation préprofessionnelle de la personnalité d'autre part.

Ce qui attire au Travail, ce n'est ni la perspective d'une carrière prestigieuse, ni celle de rémunérations relevées par des primes, c'est la simple substance de sa mission, qui rencontre une orientation personnelle. De quoi se compose celle-ci? D'abord une curiosité pour une matière nouvelle, liée à des événements sociaux généraux impressionnant des esprits jeunes: la récente législation du travail de 1936, les réformes de la Libération; ou encore un effet d'époque (la «nouvelle société» du gouvernement Chaban-Delmas (26)); ou bien, inversement, une répulsion éprouvée pour les questions économiques et financières, les questions sociales apparaissant comme une problématique alternative. Plus profondément ensuite, l'attrait pour le social exprime une disposition éthique ou affective à l'égard soit de la vie collective, soit des individus ou des groupes défavorisés (27), soit enfin du mouvement social.

De l'excellence d'un cours de faculté de droit sur les conventions collectives - ou encore du plaisir de la lecture, lors d'un enseignement de droit administratif en 1936, des rapports du commissaire du gouvernement Blum devant le Conseil d'État-, jusqu'aux enseignements de P. Durand à l'ENA(28), un tel attrait a pu prendre chez beaucoup la forme d'une passion intellectuelle activée lors de la formation préprofessionnelle. Les «puissants démons de la connaissance et de l'action » (DURAND, 1953, p. 618) sont nourris de l'expérience réfléchie vivante des fonctionnaires sociaux (29) qui enseignent à l'ENA

(24) Il part en 1974.

(25) À cette catégorie d'agents s'ajoutent ceux qui sont entrés au moment de la Libération (Jane Boy, Simonne Leportois....). (26) Sur décision du Premier ministre, la promotion $1968 \mathrm{de}$ l'ENA (sortie en 1970) fut affectée pour un an en totalité aux ministères sociaux.

(27) AO-M 10A, p. 17.

(28) De ces enseignements a été tiré le grand ouvrage de P. DURAND (1953).

(29) AO-M 8, p. 6. 
dans l'après-guerre: Jacques Doublet (30), Pierre Laroque et Olga Raffalovich(31), Pierre Laurent alors jeune auditeur; plus tard, Bernard Lory (32) et Jacques Delors. Une telle transmission ne concerne pas seulement les futurs agents des strates centrales du système administratif: Olga Raffalovich et Pierre Demondion interviennent ainsi, de même que différents responsables de la Direction générale et de services extérieurs territoriaux, au Centre de formation des inspecteurs du travail - alors situé dans les locaux mêmes de la place de Fontenoy.

La formation en vue du concours, puis lors de la scolarité à l'ENA, qui s'avère déterminante pour l'orientation future - au point de se souvenir encore, à près de trente ans de distance, des sujets d'entrée ou de sortie, associés à ce qui a alors été assimilé (33) -, constitue néanmoins une bifurcation au sein de la «voie sociale»- on touche là au «champ de vision» (Simon, p. 210). Alors que la formation des administrateurs issus des concours de rédacteurs est exclusivement juridique, la formation sociale dispensée à l'ENA, sans ignorer le droit, le place au sein d'un champ plus étendu, dans lequel prennent place, à côté de cette discipline, la démographie, l'économie, les finances publiques, les problèmes sociaux, l'entreprise, en un mot, les sciences politiques. Se joue là l'alternative, relevée par P. Legendre, entre les deux modes de formation des orientations cognitives de l'élite administrative, opposant le droit et les sciences camérales (34) (LeGENDRE, 1992，p. 36; 531): d'un côté, l'étude des relations juridiques, à l'égard desquelles l'État est seulement un tiers régulateur, libre seulement de densifier ou d'alléger le système des règles; de l'autre côté, la maîtrise des techniques de l'action directe de l'État, ainsi que la compréhension de l'objet de cette intervention: les rapports sociaux et économiques (35). La thèse de doctorat en droit

(30) AO-M 7A, p. 11

(31) AO-M 6A, p. 2.

(32) Futur directeur général de la population et de l'action sociale.

(33) Dans la conférence de questions sociales assurée par Robert Jaussaud (ancien directeur du travail) en 1955, Jean Boudard (futur responsable de la section des études générales) planche le 7 juin sur «le problème des charges sociales»; le même jour, Gabriel Oheix est appelé à répondre à la question suivante: «Le sanitaire peut-il se dissocier du social?»; le futur membre du contrôle général fait aussi un exposé sur «La formation du système français de Sécurité sociale» (CAC 760180/16, fonds Sibileau).

(34) Dénommées en France «sciences politiques».

(35) Ainsi on relève, pour la section d'administration sociale, les sujets d'admissibilité suivants: "L'intervention de l'État dans la fixation des salaires» (concours de mars 1946), «La politique des subventions économiques» (second concours d'octobre 1946), «La stabilité de l'emploi» (second concours de 1952 - et, en admission: "La formation des élites dans le monde ouvrier»). Citons enfin, pour 1953, «Comparez les avantages essentiels obtenus par les travailleurs en 1936 et en $1945 »$ (admission, premier concours) et «Les théories de la population» (admission, second concours). Source: ENA, Epreuves, statistiques des concours, Paris, Imprimerie nationale. était tenue pour le critère supérieur de la capacité dans le système antérieur(36), c'est la maitrise élégante d'une compréhension générale des enjeux d'une politique sociale qui est désormais requise. Il s'agit moins de connaître la subtilité des règles que le contexte dans lequel elles s'insèrent. La formulation des «problèmes sociaux»; tant par les hauts fonctionnaires réformateurs de la Libération que par leurs collègues plus jeunes, diffusée notamment au sein des enseignements qu'ils dispensent à l'ENA, se distingue du «droit [vraiment] juridique» qu'est le droit du travail (37).

Alors que le « social» (38) diffusé « de l'autre côté du jardin » de la rue Saint-Guillaume s'implante dans l'administration, reléguant peu à peu le droit spécialisé enseigné place du Panthéon, divergent deux appréhensions de l'action, la posture cognitive ne prenant plus appui d'abord sur les textes (on déplore l'imprécision de la culture juridique des élèves de l'ENA(39)), mais sur les problèmes sociaux, au point que l'administrateur civil qui a quitté en 1957 le ministère pour une importante fédération patronale considère que "c'est la même maison: c'est le même bateau»(40). La divergence des deux voies - qui s'exprime sous la forme de griefs réciproques, les anciens rédacteurs déplorant l'incompétence juridique des nouveaux administrateurs, ces derniers leur reprochant une méconnaissance des problèmes économiques et du monde industriel -, se manifeste non seulement, par la suite, dans l'élaboration même des politiques, mais, très tôt, dans la différence des techniques de socialisation professionnelle, au contact des premiers supérieurs. Dans la branche juridique, l'apprentissage s'effectue par l'acquisition de la maîtrise des textes existants (41) et la participation à l'élaboration de nouveaux textes (42), tandis que dans la branche étendue du

(36) $C f$. ainsi les thèses de Pierre Demondion, chef de bureau puis sous-directeur de l'emploi et directeur-adjoint, L'artisanat dans l'État moderne, Paris, Montchrestien, 1941. Maurice Meunier, chef de bureau, La résiliation du contrat de travail pour cause de suppression d'emploi, Paris, PUF, 1941. Renée PetrT, chef de bureau, Les conventions collectives de travail: notions historiques et commentaire théorique et pratique de la loi du 24 juin 1936, Jouve, 1937. Dante Rosenthal, chef de bureau, La paix industrielle et le mouvement trade-unioniste en Grande-Bretagne, Paris, PUF, 1931. Alfred Rosier, directeur de la main-d'œuvre, La crise du logement ouvrier: le problème de l'habitation à bon marché, Bosc \& Riou, 1928.

(37) AO-M 13, p. 8.

(38) Cette approche du social a été synthétisée par la suite dans le Traité du social de J. Fournier et N. QuestiauX - tous deux membres du Conseil d'Etat -, Paris, Dalloz, 1976. Voir aussi (encore à l'état plus analytique), l'ouvrage dirigé par Pierre LAROQUE (à la deuxième édition duquel collabore Jacques Dupront), Les institutions sociales de la France, Paris, La Documentation française, 1955.

(39) AO-M 6B, p. 9

(40) AO-M 13, p. 24

(41) AO-M 10B, p. 21

(42) AO-M 13, p. 4. 
«social», il s'opère par la familiarisation avec des problématiques opératoires (43).

En ce sens l'ENA est vraiment une «école», dont le style imprime progressivement sa marque dans l'administration. Toutefois, cette opposition entre les deux voies n'est pas seulement diachronique elle se redouble du maintien d'une césure entre les modes de sélection des administrateurs centraux et ceux des futurs inspecteurs du travail, pour lesquels le droit continue d'occuper une place prépondérante jusqu'à la fin de la période (44).

\section{Le fonctionnaire comme ministre inversé}

«Le ministre, chef d'administration, homme politique » : peut-être eurent un jour à s'interroger, sur ce sujet classique au concours d'entrée, des candidats à l'ENA appelés à devenir, dans un ministère, fonctionnaires, c'est-à-dire hommes d'administration, subordonnés politiques: ministres inversés (45). $\mathrm{Si}$ les hauts fonctionnaires apparaissent proches $\mathrm{du}$ pouvoir, rien pourtant n'est plus étranger au Beruf de fonctionnaire que le métier et la vocation d'homme politique: c'est là la situation singulière du fonctionnaire, aussi radicalement distinct qu'inséparable du ministre.

Dominée par la structure de l'autorité, reposant sur la disposition à se soumettre (46), cette situation oscille entre les deux pôles de l'obéissance (47) d'une part - que ce soit sous la IVe République ou sous la Ve, on n'est directeur que par la volonté du gouvernement, mais cette disposition excède de beaucoup, vers le bas, cette fonction - , et du renoncement à la tendance à la soumission, d'autre part. Elle appelle ce que SimON (p. 128) désigne comme la «perte potentielle des idées indépendantes», attitude avec laquelle contrastent les dispositions de personnalités à l'opposé du ministère du Travail «classique» (48).

(43) AO-M 1A, p. 9

(44) De 1958 à 1964, Yves Delamotte est chargé des «problèmes relatifs à la recherche sociale» au sein de la Section des études générales. Chargé en 1969 des fonctions de directeur du Centre de formation des inspecteurs du travail, il fait pénétrer dans les enseignements des disciplines nouvelles, extérieures au droit du travail, telle la sociologie.

(45) $C f$. aussi "Les fonctionnaire et la politique»; «L'obéissance hiérarchique» (première épreuve d'admission du second concours d'entrée à l'ENA de 1960, in ENA, Épreuves..., op. cit. supra).

(46) «La caractéristique de l'autorité est qu'elle ne cherche pas à convaincre le subordonné, mais à obtenir son acquiescement» (Simon, 1965, p. 151). Cf. aussi, ibidem, p. 130.

(47) AO-M 11B, p. 25.

(48) Telle celle de Jacques Chazelle, directeur général de 1963 à 1966.
À peine se sont-il rencontrés via l'effet de promotion(49), que les chemins respectifs du ministre et du fonctionnaire s'écartent l'un de l'autre. Le serviteur s'exprime au nom du ministre, sans être un homme public ou même un homme ou une femme du monde: ni Gabriel Oheix, ni Olga Raffalovich ne figurèrent jamais au Who's who. Il faut aimer l'anonymat des notes - concises pour être lisibles en allant vite au but, non signées pour être utilisables à chaque échelon de la transmission-, devoir renoncer à être un auteur tout en apprenant à écrire, pour le discours que prononcera son "chef politique», que «la France n'entend pas ménager son effort pour un renouvellement de la problématique du progrès social [dans le cadre de l'OIT] (50)». Redoublant une certaine «timidité en public », le devoir de réserve est «absolu»; si, selon M. Weber, l'absence de conviction peut être, chez l'homme politique, tenue pour un «péché mortel» (WEBER, 1919b, p. 197), les convictions propres $\mathrm{du}$ fonctionnaire, quoique loin d'être inexistantes, "n'apparaissent pas dans le vécu administratif». Plus, fût-ce pour rendre compte, avec la neutralité convenable, de la politique voulue par le ministre, l'on se méfie de la tendance de la médiatisation à transformer, comme au moment de l'affaire Lip, en déclaration personnelle le communiqué officiel du délégué appelé à négocier: un directeur n'est pas homme d'interviews. Les rythmes d'action enfin ne concordent pas: l'administration est nourrie du précédent - les services «ont pour [eux] le temps et la mémoire» (SCHRAMECK, 2006, p. 97) - , poursuivant jour après jour la lente accumulation cohérente des réponses de droit aux questions de fait, quand le ministre s'en tient à la nouveauté : la traduction en textes - donc en questions de droit - de réponses à des faits sociaux. Dans cette distance réside la singularité de l'identité du fonctionnaire, à l'abri des risques subis par l'«entrepreneur politique», mais porteur du poids de la continuation institutionnelle.

Dès sa préparation au concours, le candidat à l'école a appris, en préparant cette figure obligée qu'est la note de synthèse - parfois «pour le directeur de cabinet»-, à revêtir l'habit d'un proche $\mathrm{du}$ pouvoir. Arrivé maintenant au bureau des Conventions collectives, le voilà établissant, en

(49) On parle ainsi de «mon camarade de promotion, l'actuel président de la République». Celui-ci n'était pas dans la même section - le délégué à l'emploi lors de l'affaire Lip a aussi, dans sa propre section sociale, eu dix minutes pour exposer «Les origines du système français de Sécurité sociale», juste après que son "camarade de promotion" Jean Charbonnel, futur ministre de l'Industrie de la même affaire Lip, s'en fût voir attribuer cinq pour «Le système des États-Unis» (CAC 760180/16).

(50) Intervention de M. Gilbert Grandval à la conférence de l'OIT, Genève, 14 juin 1966, in Revue française du travail, avril-juin 1963, p. 8. (NB: l'intervention a été rédigée par l'un des administrateurs de la section des études générales). 
août 1950, un tableau comparatif des propositions syndicales en matière de budget-type alimentaire et non-alimentaire, faisant la moyenne des prix de la margarine et du kilogramme de pommes de terre, calculés de manière divergente par la CGT et par la CGT-FO(51). Si la rhétorique sur le "pouvoir d'achat» est, quant à elle, réservée au ministre, qu'il s'agisse de la préparation d'un dossier, de la présence, assis sur le banc des commissaires du gouvernement, aux séances de l'Assemblée ou du Sénat ou, honneur éprouvant, de la participation, aux côtés du ministre et répondant (sur sa demande) à sa place, lors d'un débat devant une commission parlementaire sur une ordonnance relative à l'indemnisation du chômage (52), le métier ne permet pas d'ignorer l'élaboration d'une politique générale. Aussi la qualité cognitive attendue consiste-t-elle à faire entrer le savoir administratif dans l'«intelligence de la situation ». C'est là le paradoxe - se trouver dans un système politique tout étant obligé par la réserve; comprendre l'expression politique mais ne pas s'engager (53) -, qui sous-tend la position $\mathrm{du}$ fonctionnaire, et particulièrement $\mathrm{du}$ directeur, défini par la mise en relation des orientations politiques du ministre et des catégories juridiques et financières, "langue de travail naturelle» de l'administration. Mais aussi traduction, en termes politiquement opératoires pour le ministre (54), de ces mêmes données ainsi que des constats factuels issus de la vie des services, centraux comme de terrain.

Les interactions, constantes mais inégalement intenses, entre deux positions si distinctes ne sont pas limitées aux directeurs, invités à participer à la réunion hebdomadaire du lundi matin(55). Même s'il arrive que le chef du bureau de la FPA soit régulièrement appelé chez un ministre soucieux de suivre lui-même l'état hebdomadaire de la construction de sections de formation, ou encore qu'un sous-directeur soit convié à déjeuner par «son» ministre avant une réunion de ce dernier à Bruxelles pour un Conseil, voire qu'un agent supérieur soit, à l'occasion, directement appelé au téléphone par un jeune secrétaire d'État à l'Emploi, les interactions entre le ministre et son administrant ne passent que rarement par le face-à-face - et le plus souvent en ce cas par l'intermédiaire du cabinet. Il n'est pas dans les usages que l'autorité prenne la forme de l'ordre: tout repose sur l'acquiescement anticipé. Il faut, parfois, pouvoir, tout en baissant le nez, répondre à la commande du conseiller: «Bien, monsieur»: les manifestations

(51) CAC 770315/12: "Institution du SMIG et du budgettype 1950, tableau établi par madame Seeuws ».

(52) AO-M 5A, p. 17.

(53) «C'est peut-être ce qu'on appelle le sens de l'État; si l'on ne peut pas s'adapter à des situations pareilles, il ne faut pas choisir la fonction publique. "

(54) AO-M 1B, p. 15.

(55) AO-M 11B, p. 8. ouvertes de désaccord demeurent très inhabituelles. Elles peuvent néanmoins exister (56), indiquant que la disposition à l'obéissance peut s'accompagner du maintien d'«idées indépendantes» (Simon). Quoi qu'il en soit des conflits éventuels, le fonctionnaire demeure lié au ministre par ce qui est plus qu'un devoir d'obéissance: un consentement à l'autorité.

Le rapport d'inversion éloigne la concurrence entre les deux «hommes»: dans sa discrétion, le fonctionnaire n'a pas la vision d'un homme politique, et «de toute façon la décision nous échappe»; dans sa conviction, l'homme politique ne possède pas nécessairement l'expertise, et il n'est pas sûr qu'il « décide». L'inversion se réalise dans la tension entre l'obligation et le consentement - «personne n'est obligé d'être directeur»-mais "vous êtes fonctionnaire, donc vous suivez les ordres». Mais suivre «les ordres » ne signifie pas être « aux ordres» du ministre: le directeur est souverain et n'en réfère pas nécessairement à cette dernière instance, même s'il détient la signature du ministre. Le consentement n'est pas automatique: "Vous faites vos observations ", et l'on peut même ne pas souhaiter poursuivre une fonction sous l'autorité d'un ministre dont on ne partage pas les visions (57). S'il demeure que le conflit entre l'indépendance et le consentement se résout dans la loyauté, celle-ci n'est pas l'obéissance mécanique mais un compartiment de la divergence potentielle.

Le fonctionnaire n'est pas un homme de pouvoir (politique), ni non plus l'homme du pouvoir; il n'est pas pour autant un homme sans pouvoir. Pierre Laurent, tout en réorganisant administrativement sa direction, développe une conception personnelle du renouvellement de la politique de la main-d'œuvre et de formation professionnelle(58) - antérieurement à l'accession de Gilbert Grandval à la charge du ministère. Le même homme poursuit la même idée lorsque, devenu à partir de 1963 secrétaire général de l'Éducation nationale, il est, sous l'autorité du ministre Christian Fouchet, un promoteur de la création des IUT, opérée par le décret du 7 janvier 1966.

(56) On a déjà mentionné la fronde des anciens de l'ENA face à l'arrêté Grandval-Chazelle du 16 décembre 1965 réorganisant la DGTE; ils en appelèrent alors jusqu'à Louis Joxe, ministre d'État chargé de la Réforme administrative (à la suite de cette initiative, le directeur général demanda au responsable de la section du ministère des anciens élèves de l'ENA de suspendre ses enseignements dans cette école). $C f$. aussi, pour un cas beaucoup plus récent il est vrai (à propos du projet de transfert, en 1993 de la tutelle de l'AFPA de la Délégation à l'emploi à la Délégation à la formation professionnelle): AO-M 5A, p. 9. (57) Pierre Laurent choisit ainsi de quitter le secrétariat général de l'éducation nationale lors de l'arrivée d'Edgar Faure à la tête de ce département en 1968 "nous n'avions pas toujours les mêmes visions, nous l'avions déjà constaté dans l'affaire marocaine». (AO-M 8, p. 5).

(58) Il met en place des sections de formation de niveau supérieur au sein de la FPA. 
La disposition à obéir n'est, ainsi, pas l'absence d'initiative, encore moins l'immobilisme. Se saisissant de la proposition d'un chef de bureau, le directeur peut la soumettre au ministre, guettant le moment, survenant lors d'une réunion, où ce dernier s'interrogera à haute voix sur la manière de résoudre le problème déjà posé: il n'est ainsi pas rare, dans la vie administrative, que - comme l'ont montré J. MARCH et J. Olsen (1976, p. 31-34; 239245) - des solutions cherchent des problèmes. «Eh bien oui, faites-moi une note !»: cette parole est déjà un achievement. Au cœur de cette relation, se trouve une confiance interpersonnelle, à la base de ce qui unit leur ministre et ses fonctionnaires, co-participants de la «deuxième branche» du gouvernement: l'exécution.

\section{Le poste et l'exécution}

En septembre 1966, lors de l'épreuve de «Premier jour» (59) du concours Fonctionnaires, les candidats à l'entrée à l'ENA eurent à se demander « dans quelle mesure les difficultés que la France a connues depuis la fin de la Deuxième Guerre mondiale relèvent [...] d'une inadaptation au changement» (60): les thèses de M. Crozier, qui avait toujours affirmé la nature clinique de la sociologie des organisations, pénétraient la réflexion administrative. La même année, l'auteur du Phénomène bureaucratique (CROZIER, 1963), qui dirigeait alors une série d'études, financées par la DGRST, sur les administrations françaises, écrivant que «le problème du changement est un des problèmes majeurs de la sociologie» (61), présentait aux lecteurs de Sociologie du travail de premiers résultats (Sociologie DU TRAVAIL, 1966). Parmi ceux-ci, les conclusions de l'enquête menée par J. Lautman et J.-C. Thœnig sur «une administration centrale $($ «X») confrontée à des contraintes d'adaptation aux modifications de son environnement (62). Au-delà des conflits de pouvoir au sein de la DGTE, alias «X», la structure bureaucratique, confrontée aux nouveaux éléments de la relation entre fins externes et cadres cognitifs internes, ne s'avérait plus capable de garantir l'« unité d'action »,

(59) Nom courant alors donné à la composition de culture générale (dite par la suite «troisième jour»).

(60) Source: ENA, Épreuves des concours de 1966, Paris, Imprimerie nationale, 1967.

(61) «Crise et renouveau dans l'administration française», Sociologie du travail, 1966, p. 227.

(62) Michel Crozier est à cette époque membre du comité directeur du Club Jean-Moulin. Lui-même et Jacques Lautman participent, lors des journées annuelles du Club les 12 et 13 octobre 1963 à Royaumont, à la Commission «réformes administratives», qui discute du rapport Sept projets pour entrer en démocratie, suggérant la création d'un ministère du Développement administratif et d'un ministère de la Reconversion [industrielle], qui s'inspirerait des méthodes du Commissariat du Plan (archives du Club Jean-Moulin : 6 CJM$1)$. voulue par Pierre Laurent dès 1957, et nécessaire à un « appareil d'État harmonisé» (LAUTMAN, THENIG, 1966, p. 316).

En se situant sur un second plan (les fonctionnaires en travail) - le rapport des individus à la structure interne (l'organisation) et à l'activité proprement dite (le travail) - , on est conduit à mettre en doute la réduction de l'activité des bureaux à la «bureaucratie». Si l'exécution est l'action de porter une opération à son achèvement, ce processus peut relever de la stricte application des directives (la «pure exécution»), ou bien consister en un accomplissement personnel.

\section{Stratification du travail et unité d'action}

R. Grégoire observait en 1954 que, si la réglementation de la fonction publique est distincte des mesures d'organisation administrative, elle reste conçue à partir de cette organisation (GREGOIRE, 1954, p. 127), définie par la hiérarchie, répartissant l'autorité sur des échelles verticales. Projetée dans l'espace concret de l'action des services, une telle distribution se constitue en strates, qui réalisent le cadre formel de l'organisation. Cette «stratification» du travail n'obéit pas aux critères classiques de la division de l'activité entre concepteurs et exécutants, accompagnée d'une parcellisation routinière des tâches de ceux-ci - critères retenus par M. Weber dans son modèle de la bureaucratie (Weber, 1922). En laissant de côté les catégories les plus basses - latérales par rapport à la matière du travail administratif -, il existe au contraire une unité du travail du haut en bas - et mieux, du bas en haut-de l'échelle de l'autorité, du directeur au secrétaire d'administration (63), une «unité d'action», qui s'appuie sur la liberté relative des unités élémentaires, les bureaux.

Cette liberté ne s'oppose pas à la hiérarchie; bien au contraire, c'est celle-ci qui, en tant que structure d'acceptation réciproque, garantit la coopération entre les unités et permet à l'organisation de fournir les outputs attendus. Une telle structure est comparable à celle qui relie la direction générale de la Centrale et la direction départementale: celleci n'est pas une ramification de celle-là, mais un microministère en charge des différents versants de l'action du travail: application des règles et placement et formation de la main-d'œuvre (LuCOT, 2000).

"M'en parler»: la note venue du cabinet est arrivée à la sous-direction, puis sur la table du chef de bureau, avec ces mots écrits en marge d'un paragraphe. Entre cette demande laconique et la «parole», il y a toute l'étendue du travail du bureau. Alors que, dans la «division du travail» classique, il

(63) Ce corps a précédé celui des attachés d'administration centrale. 
existe une double spécialisation (selon la nature des tâches, définie en niveaux de qualification; et, au sein de chaque niveau mais surtout des niveaux les plus bas, des tâches les moins qualifiées en opérations élémentaires), l'ensemble du travail est, ici, réparti au long des échelons hiérarchiques, sans pour autant se décomposer en épousant cette logique-là : on peut caractériser ce système, dans lequel chaque échelon est responsable de la finalité du travail, comme un système de la "charge», celle-ci étant, comme le veut la langue française, une «fonction dont on a le soin».

C'est «en bas», dans les strates profondes du bureau, qu'est constitué le dossier, support de l'élaboration des textes ou des choix d'allocation budgétaire (investissements de FPA). Quel que soit le niveau hiérarchique, les tâches accomplies sont de même nature. Au sein du bureau, on travaille ensemble sur les mêmes dossiers : le jeune rédacteur - devenu agent supérieur de troisième classe - prépare lui-même les dossiers de l'ordonnance sur les comités d'entreprise, "tient la plume» de la loi de 1950 sur les conventions collectives, contribue avec Renée Petit ou Olga Raffalovich elle-même à proposer des termes ou des formules rédactionnelles adéquats - entre lesquels choisira le cabinet du ministre -, rédige en 1952 les notes préparatoires à la loi Pinay sur l'échelle mobile (64). La différence hiérarchique se marque au degré inégal d'intervention dans les segments «signalés» du dossier, telle l'analyse, pour le ministre, d'un contre-projet présenté par un groupe parlementaire (65). Une encore jeune agent supérieur est directement associée, aux côtés d'une sortante fraîchement émoulue d'une des premières promotions de l'ENA, aux réflexions de Francis Netter(66). Et le sous-directeur des relations professionnelles, Olga Raffalovich, tout en assurant une relecture, substituant de son écriture assurée un terme plus adéquat à un autre déjà pourtant mûrement réfléchi, "respecte la compétence» des attachés ou des administrateurs qui, dans les bureaux, "doivent être capables de rédiger un texte». Comme l'atteste l'expression courante de «remontée», le processus de travail n'est pas orienté du sommet vers la base, mais des bureaux vers la direction - c'est là l'une des missions principales des chefs de bureau: transmettre textes, dossiers et courriers en provenance de son unité à l'échelon supérieur, et en recevoir

(64) CAC 860561/1.

(65) «Analyse critique du contre-projet de Madame Devaud (groupe RPF du Conseil de la République), note pour M. le Ministre» (NB: RP= Renée Petit; CAC 860561/1).

(66) Polytechnicien, spécialisé dans l'actuariat, qui joue un rôle déterminant dans l'élaboration de la Sécurité sociale aux côtés de Pierre Laroque. les observations (67). De toute façon, «tout travail est collectif dans l'administration », une dimension collective étayée par l'uniformité de la formation reçue et les filtrages de la "remontée» d'une part, le poids du passé (on archive de manière systématique)(68) d'autre part.

On ne peut pour autant parler d' «autonomie» ou de «liberté» des unités élémentaires: celles-ci ne définissent pas leurs propres normes, ni ne jouissent d'un pouvoir propre d'appréciation. Elles sont en revanche responsables de leurs tâches - dans le sens où un organe est chargé d'une fonction. Ce système de la «charge» repose, d'une part sur la «solidité» des « collaborateurs» («des gens [...] capables, dans les 24 heures, de mettre sous les yeux [...] le paysage effectif correspondant à la question posée»)(69), d'autre part sur la confiance qui leur est accordée par le supérieur: ce dernier laisse faire, car il sait qu'il n'y aura pas d'écarts: les fonctionnaires «ne font pas de bêtises» (70).

Car la «charge» est aussi un poids contraignant: si la coopération au sein de ce système comporte - en tant qu'elle suppose la confiance entre les personnes - un volet de "laisser-faire», elle suppose aussi, en tant qu'elle est structurée par une hiérarchie de l'autorité, une abdication devant le «droit au dernier mot» (SImON, p. 129), particulièrement sensible dans un monde dans lequel règne l'écrit. L'autorité surplombe les unités chargées de la tâche commune; d'où l'importance de l'emplacement des bureaux: que l'on soit localisé dans Estrées ou dans Lowendal, où s'étendent à l'infini les services, il vaut mieux ne pas se trouver trop loin des portes battantes donnant accès à la rotonde, là où, protégé par le secrétariat, s'étend le bureau du directeur: moins de chemin à faire si l'on est appelé, et une chance d'être vu. Dès lors, la non-insertion des «chargés de mission» de l'époque Chazelle dans une telle structure - quoiqu'ils aient (et surtout parce qu'ils ont!), directement accès au directeur - , apparaît comme une hérésie organisationnelle (71): ils sont des «chargés» hors « charge». De même, les structures hors bureaux, telle la section des études générales, dévolue à des travaux à la demande du

(67) Le contrôle est assuré a posteriori, au moyen des rapports d'activité établis par les bureaux eux-mêmes, chiffrant annuellement le «nombre de réunions auxquelles participe l'agent supérieur», ou le volume du courrier arrivé et expédié, ventilé en fonction de son contenu (des simples lettres de transmission aux «pièces de conception» en passant par l' «application des textes» ou les «réponses de politesse»). («Activités des bureaux de la sous-direction des professions sociales », période du deuxième semestre 1973, archives de la Direction de l'action sociale, non répertoriées).

(68) AO-M 10A, p. 16

(69) AO-M 8, p. 7.

(70) AO-M7B, p. 6;9;16

(71) AO-M 3A, p. 18. 
directeur(72), sont-elles mal perçues par les chefs des bureaux établis.

L'exécution, on le voit, n'a rien d'une application mécanique. La hiérarchie suppose aussi initiative personnelle, dans les deux sens: à la limite, l'ensemble peut fonctionner sur sa lancée propre sans commande explicite: qu'il soit directeur à la centrale ou directeur régional, il faut que le directeur, lui aussi, prenne l'initiative de diriger ses services, faute de quoi le courrier sera réparti avant qu'il n'en aie eu connaissance (73).

Stratifié et unifié à la fois, ce système n'est pas coordonné par le commandement, mais par un équilibre d'acceptations réciproques (SIMON, p. 127). La cheville ouvrière en est le sous-directeur, à la fois parce qu'il est plus stable que le directeur et parce que sa carrière elle-même est à l'image de la «remontée»: ancien chef de bureau après avoir été simple rédacteur ou administrateur, il provient du cœur des services. À la confiance envers le subordonné répond la légitimité du supérieur: l'autorité est bien consentement à l'obéissance volontaire. Le chef de bureau est maitre de son domaine clos; le sous-directeur supervise; le directeur reçoit les demandes du ministre et lui transmet le produit contrôlé de ses services. A contrario, la dynamique de ce système "ad-ministratif» repose sur la «commande» ministérielle; que celle-ci vienne, comme en mai et juin 1968, à défaillir, et le ministère du Travail n'est plus qu'un ensemble de bureaux sans travail.

Cette organisation se contre-distingue de la bureaucratie. C'est ainsi que, même après son passage en cabinet ministériel, le poste de directeur de la planification à l'AFPA, occupé par un administrateur civil dans le cadre de sa mobilité, lui apparaît rétrospectivement comme "une expérience de vrai commandement»-alors pourtant qu'il a, depuis, exercé des fonctions de direction au travail (74). C'est une constante: les directeurs ne raisonnent jamais comme des responsables de personnel, et pour des raisons plus profondes que la situation statutaire des agents, extérieure au régime du droit du travail. Si le rôle de la hiérarchie est décisif dans la résolution du paradoxe de l'étanchéité des niveaux et de l'unité de l'action, ce sont d'autres facteurs (la force de la

(72) Qui prend en 1961 la suite de la section des affaires générales - constituée au travail en 1957 à partir d'attributions de bureaux de la direction de la main-d'œuvre.

(73) AO-M 2A, p. 11; AO-M 8, p. 2.

(74) «Ça n'avait vraiment rien à voir avec ce que j'avais fait pendant quatre ans au ministère, [...] il s'agissait d'un travail d'organisation [...], une fonction de commandement d'équipes beaucoup plus volumineuses c'était un métier de "manager" " (AO-M 1A, p. 13). Cette expérience est éclairée en contrepoint par celle d'un directeur départemental: «Ce qui était le plus préoccupant, ce n'était pas un conflit [du travail] important. Tandis que le fonctionnement interne de cette [maison] de cent personnes, avec des agents [...] assez remuants, c'était devenu ma première préoccupation" (AO-M 2A, p. 11; 2B, p. 18-19). socialisation préprofessionnelle - opérée par le droit ou par l'école -, le partage d'une communauté de valeurs) qui préviennent la formation de «politiques organisationnelles» (SIMON, 1965, p. 149), aboutissant à des divergences et rompant l'unité d'action.

Tel est l'univers, tout à la fois cloisonné (on ne se rencontre pas entre bureaux, sauf de manière informelle pour commenter, le long de l'un des deux couloirs de l'étage, une nouvelle incertaine: "Vous savez ça? »), et communiquant (par la note), fondé sur la hiérarchie et sur la responsabilité, stratifié et unifié, mobilisant un travail tour à tour spécialisé et polyvalent, autoritaire sans commandement, œuvrant de manière lente mais réactif aux demandes urgentes, que découvre Pierre Laurent lorsqu'il devient directeur général en février 1957. Ce juriste, venu du Conseil d'État (où il était entré par l'un des tout derniers concours directs), entreprend aussitôt de moderniser cette administration qui lui apparaît très traditionnelle, en optant pour la voie de la centralisation. C'est le sens de la réorganisation voulue dès sa prise de fonctions - et réitérée dans l'arrêté du 21 avril $1961-$, qui se traduit notamment par la suppression des deux fonctions de directeur et la création de la division de Coordination, directement placée auprès du directeur général, à un niveau que l'organigramme marque comme clairement supérieur à celui des sous-directions. Mais il agit avec prudence: l'administration est une "mécanique de précision », qu'il faut se garder de brusquer(75).

Le successeur de Pierre Laurent, Jacques Chazelle (normalien et conseiller des affaires étrangères), a, en même temps que lui - mais dans des fonctions d'information -, participé à l'administration d'occupation de la Sarre et à l'administration coloniale du Maroc, aux côtés de Gilbert Grandval - dont il est en 1962 le directeur de cabinet au ministère. Devenu directeur général alors que la loi instituant le FNE est sur le point d'être adoptée, il poursuit, dans ce contexte, le projet de modernisation organisationnelle, mais selon une toute autre voie réformatrice, celle du «management» avant la lettre, tout en donnant le primat à la nouvelle fonction emploi(76). Cette transformation de l'organisation est poussée plus loin encore par l'arrêté du 16 décembre 1965, établissant un redéploiement

(75) AO-M 8, p. 16.

(76) La division de Coordination fut supprimée, tandis que le service naissant de l'Emploi fut directement rattaché au directeur général, son chef, Claude Thomas, devenant l'adjoint immédiat de ce dernier, à un niveau supérieur à Olga Raffalovich, pourtant directeur adjoint pour le travail. Il faut noter que ces évolutions fonctionnelles sont parallèles à l'introduction d'interactions personnelles d'un style nouveau: là où Robert Jaussaud, exerçant alors la fonction de directeur, s'adressait, en 1946, à Olga Raffalovich selon les formes les plus classiques de la courtoisie administrative ( $J$ J'ai l'honneur de vous transmettre...»: CAC 770315/12). Claude Thomas tutoie Jacques Chazelle ("Veux-tu jeter un coup d'œil...?») (CAC 880594/1: Comité supérieur de l'emploi 1964). 
décentralisé des responsabilités en quarante-quatre fonctions (77), diluant l'autorité des sous-directeurs et l'identité des unités traditionnelles; les initiatives de Jacques Chazelle (lancées au moment où - tandis que certains services de l'administration commencent à s'engager dans la $\mathrm{RCB}(78)$ - le travail devient, via le FNE, une administration dépensière) annoncent la création, près de dix ans plus tard, de la Délégation à l'emploi et surtout l'organisation en pôles de la mission emploi, dirigée dès 1975 par Dominique Balmary. Elles furent sur le moment, on le sait, vivement contestées par les administrateurs, notamment ceux de la sous-direction des rapports économiques et sociaux du travail(79), attachés au système de la «charge » fonctionnelle des bureaux et à leur contrôle. Jean-Marcel Jeanneney ne maintint pas, en 1966, dans ses fonctions de directeur général, Jacques Chazelle, "lequel au demeurant n'était pas juriste»: un homme de 1' "action» davantage que du texte (80).

\section{«Les textes » et le métier}

Qui, dans la vie administrative - des sommets de l'État à la moindre des commissions locales - n'a jamais entendu, de manière récurrente, le plus limité des débats être étayé de la référence verbale aux «textes»? «Les textes»: voilà la substance intime du travail, au travail, en 1956: le cœur du métier. Les textes même davantage que "la loi»-celleci est affaire de juge ou de gardien de l'ordre. Le «texte», c'est cet ensemble agrégeant à la loi-le plus souvent préparée par les fonctionnaires, mais amendée et votée par le Parlement - le décret et la circulaire, œuvre des bureaux et référence majeure de l'administration: ne serait-ce que parce que c'est lui (ou les décisions qui en résultent) qui engage l'action et peut - lorsqu'il a un caractère réglementaire - être examiné par le juge administratif. Si ce phénomène n'est pas propre au travail, qu'en estil - en nous en tenant au plan formel de l'«exécution »-, dans le travail d'un ministère qui est une expression typique de ce phénomène?

(77) $\mathrm{Au}$ lieu de vingt et une dans l'arrêté Laurent du 21 avril 1961.

(78) Les opérations RCB, reposant «sur l'analyse des missions et de l'adéquation des structures en vue d'une "redéfinition précise de la politique à suivre" et d'un "nouveau style de direction", ont été expérimentées dès 1964 et généralisées par décision gouvernementale en mars 1968. La RCB se veut un instrument au service de la mise en œuvre de "projets planifiés" ». $C f$. RCB, Bulletin interministériel pour la rationalisation des choix budgétaires, septembre 1970, p. 9 et ss.

(79) La sous-direction B de J. LAUTMAN et J.-C. ThoenIG (1966).

(80) C'est d'ailleurs dans une structure «de mission»- le Commissariat du Plan - que Jacques Chazelle poursuivit son implication dans la politique économique de l'emploi (comme conseiller auprès du commissaire), avant de devenir en 1968 directeur du CNIPE, puis de revenir, en 1971, à la carrière diplomatique.
Pensés comme générateurs de cohérence, les textes constituent une matrice générale de l'action. Même si l'action du ministère consiste alors déjà, aussi en une offre de services (par exemple la formation professionnelle), cette offre elle-même et l'action des services de terrain sont déterminés par un cadre juridique; c'est pour surveiller l'effectivité des normes en vigueur que ces derniers ont été constitués. L'application de la loi elle-même dépend de la parution des décrets, signés du ministre mais préparés par les bureaux.

Si les textes sont créés par le dispositif matériel de l'exécution, leur structure se projette dans l'organisation elle-même: l'élaboration et l'application des textes ont aussi une fonction interne, une fonction de coordination de facto de l'activité des unités autonomes. Il n'est pas rare qu'un même texte mette en jeu les charges de deux ou plusieurs bureaux appartenant à des sous-directions différentes : ainsi, la loi du 11 février 1950 concerne aussi bien le bureau des conventions collectives que celui des salaires. Cette coordination d'unités distinctes s'opère sans mécanisme d'interface ou d'interaction concrète entre les bureaux; elle repose sur la structure même du texte juridique. Un bureau ne traite que de sa charge attribuée, et le chef du bureau du contrat de travail, non seulement se garde d'empiéter sur la moindre attribution du bureau des Salaires, mais encore de solliciter l'avis de ce dernier: la maîtrise de la matière juridique permettra que se réalise l'ajustement final.

«Vingt fois sur le métier remettez votre ouvrage: polissez-le sans cesse et le repolissez; ajoutez quelquefois, et souvent effacez.» Quel rédacteur, quel administrateur formé aux lettres n'a pas songé à L'Art poétique, et à l'exhortation de Boileau? Le métier est à la fois un instrument et - pour reprendre un terme dû à P. Naville - un ensemble d'«actes éduqués»: comment le travail des textes aboutit-il aux textes du travail?

S'il est de l'essence du texte d'être sous-tendu par une structure logique implicite, c'est d'une adhésion commune à sa valeur que surgit la concordance finale. Valeur matérielle certes : les différentes générations présentes au ministère dans la période $\mathrm{du}$ cinquantenaire sont solidairement gardiennes du patrimoine législatif et réglementaire du Front populaire et de la Libération. Mais surtout valeur formelle: l'élaboration des textes repose sur un dispositif de pensée; les catégories juridiques sont aussi une «technologie de l'esprit» (81). La compétence mobilisée n'est pas celle du raisonnement juridique développé par le juge; elle est une compétence de formulation, déterminante car un texte de droit du travail doit, à la fois, exprimer l'orientation

(81) L. Sfez, «Comment maîtriser les technologies de l'esprit?», Le Monde, 23 avril 1986. 
politico-sociale d'un ministre, et constituer une référence commune pour des parties, individuelles ou collectives, engagées dans l'affrontement de leurs intérêts. Avant que le jeune rédacteur ne soit laissé seul devant sa large feuille de papier-ministre, il est formé et re-formé par le chef de bureau. La formation se fait sur le tas; les nouveaux administrateurs préparent le texte de la loi de 1950, ses décrets, les arrêtés. De manière ferme et certaine, le chef guide la main de son jeune collaborateur encore novice, lui faisant toucher au plus profond de l'univers de la règle: poser les antécédents, atteindre la rectitude, se tenir à la précision(82), maitriser le style, rédiger "d'une manière parfaite». C'est là «un travail bien fait, un travail sérieux, un travail de mémoire ». On écrit, on relit, on corrige; la dactylo retape indéfiniment les originaux avec leurs pelures - transmission aux échelons supérieurs et archivage au bureau d'ordre obligent. Aucun papier ne quitte le bureau sans que son chef ne l'ait relu et corrigé de la première à la dernière ligne. "On faisait des textes clairs » : cette expérience-là est déterminante pour tous les fonctionnaires entrés au travail dans une phase précoce de la période.

Entre la demande gouvernementale et sa publication finale, l'édifice du "texte», déjà issu des multiples transmissions, ascendantes jusqu'au cabinet, puis descendantes pour réécriture, accompagnant la première rédaction, ayant circulé dans les navettes avec d'autres départements (agriculture, industrie, intérieur justice selon les cas), ou directement discuté en réunion interministérielle, éventuellement soumis aux instances consultatives compétentes. Édifice maintes fois rebâti au cours de ce processus: en témoignent à l'envi les chemises gonflées de pelures, fruit de "cet exercice de distillation fractionnée » qu'est le travail de rédaction, celle-ci se raffinant de réunion en réunion, "objet d'un examen commun pour en apprécier la cohérence». C'est «une présentation [...], un mode d'écriture et un mode de lecture [...]», tendant à une cohérence (83). Demeure l'examen - décisif - de passage devant le Conseil d'État. Il n'est pas toujours facile - mais cela vaut mieux pour la réputation - , d'emporter l'assentiment de la section sociale, ou encore en sus, s'agissant d'un texte de loi, de l'assemblée générale, même lorsque le texte présente un degré déjà élevé de qualité juridique. Moment d'appréhension: parfois le texte est renvoyé purement et simplement; parfois le voilà modifié par la section compétente; parfois, il "passe»-mais parfois "c'est à deux doigts »; devant ses collaborateurs, le sous-directeur ou le directeur a, alors, dû recevoir le «sermon, paternel mais ferme» administré par le président de la section sociale. D'autres fois encore - reconnaissance de la virtuosité rédaction-

(82) AO-M 10A, p. 19

(83) AO-M 1B, p. 15. nelle - , c'est «haut-la-main». S'il n'est pas indifférent à cet égard que le directeur soit lui-même un maître des requêtes, à même d' "impressionner ses collègues », il vaut encore mieux, pour échapper au renvoi, assorti du désagrément de remarques pouvant être «dures», que le mouvement itératif du bas en haut et du haut en bas de la hiérarchie, caractéristique de l'organisation "stratifiée», ait abouti au bannissement de l'approximation, à l'éviction de l'imprécision, à la cohérence avec le dispositif déjà existant. Restera encore à affronter la commission parlementaire saisie du projet. L'appellation de «rédacteur» a pu disparaître des cadres centraux; la rédaction est consubstantielle au travail administratif(84). Dans le caractère non pas linéaire, mais unitaire, de ce travail, réside un fondement sûr de l'«unité d'action» dont J. Lautman et J.-C. Thœnig observent, en 1964, l'affaiblissement progressif.

Déjà présentes avec la formation professionnelle (dont, davantage que la règle de droit, l'instrument opératoire est le centre et la section(85)), des logiques hétérogènes à la substance du texte, associées au renouvellement, à partir de 1963, de la politique de l'emploi, sont en effet affirmées par les personnalités qui promeuvent celle-ci au sein de la DGTMO - laquelle est devenue, en octobre 1963, la DGTE. Rapidement, la présentation, en section sociale du Conseil d'État, des textes réglementaires d'application de la loi du 18 décembre 1963 sur le FNE(86) s'avère malaisée; la section ne manque pas, en diverses occasions d'émettre des réserves sur les écarts des textes projetés par rapport aux «sûretés juridiques» habituelles du Code du travail. À la différence de Léon Frézouls et de Pierre Demondion, tous deux juristes, dûment faits docteurs par la faculté de droit, Claude Thomas, venu - en même temps que Jacques Chazelle - du cabinet de Gilbert Grandval(87) à la DGTMO, pour devenir chef de service du FNE puis adjoint au directeur général, est un ancien sous-directeur des Personnels civils au secrétariat aux Forces armées (marine), où il avait eu notamment en charge les problèmes d'administration des personnels ouvriers employés

(84) Cf. encore aujourd'hui le cadre d'emplois des rédacteurs territoriaux, recrutés sur des concours comportant eux aussi la «composition d'ordre général» et la «note de synthèse».

(85) Evalués en millions de francs 1966, les crédits d'investissement de la formation professionnelle passent en moyenne annuelle de 8,89 pour la période $1947-1949$ à 51,05 pour la période 1950-1959, et 448,35 pour la période 1960-1966. Source: P. Fournier, «Problèmes actuels de la formation professionnelle des adultes», in Revue française du travail, $\mathrm{n}^{\circ}$ 3, juillet-septembre 1966, p. 17.

(86) Récapitulés dans l'instruction du $1^{\text {er }}$ septembre 1965, visant cinq décrets et deux arrêtés. (Textes officiels, série A, Travail et Emploi, $\mathrm{n}^{\circ}$ 5, 5 bis, 5 ter, 1965).

(87) Claude Thomas était, dès 1959, entré comme conseiller technique au cabinet du ministre du Travail, Paul Bacon. Il a appartenu ensuite au cabinet de Gilbert Grandval. 
dans les arsenaux (88) - lesquels avaient fait face, de manière récurrente depuis 1946, à des problèmes de reconversion(89). Perçu par les administrateurs du secteur emploi comme doté d' "une expérience de la politique industrielle », il n'est pas un homme du texte, mais un homme de l'action tournée vers le monde extérieur (90). Jacques Chazelle et Claude Thomas ne sont pas les seuls «non-juristes-nonmembres du ministère»: un ingénieur venu de la SNCF, Desroy, entre au service de l'emploi, et Yves Chaigneau, économiste venu du commissariat au Plan, devient chargé de mission pour les affaires économiques auprès de Jacques Chazelle (91), qui s'entoure également d'un chargé de mission pour les affaires internationales - deux fonctions que Pierre Laurent avait, pour sa part et sous d'autres appellations, intégrées dans son organisation pyramidale. Dès 1964, la direction est réorientée autour de la fonction emploi (92); sur les six personnes composant le groupe dirigeant, quatre sont extérieures au travail, dont le directeur et son premier adjoint, Claude Thomas (93).

Une logique comparable semble également pénétrer, bien plus tard, le Travail lui-même, lorsqu'est créée, en 1975, la section de la politique générale du travail - orientée vers une politique extrajuridique du travail(94), concrétisée entre autres par la création de l'ANACT en décembre 1973 -, confiée à Pierre-Louis Rémy, et qui semble être, à quinze ans d'écart, comme le pendant du bureau de

(88) Affecté en 1952 au groupe des Personnels civils à la marine, il est en 1955 responsable du bureau de la Politique ouvrière et professionnelle, puis sous-directeur en 1958.

(89) $C f$. F. MARquiÉ, «La reconversion des chantiers et arsenaux de la marine (1946-1953)», Revue historique des armées, $\mathrm{n}^{\circ} 220,2000$, p. 112-127.

(90) «Ce qu'il m'a appris, c'est que [...] le métier du fonctionnaire de l'emploi, il était [...] de garder sa porte ouverte [...] de recevoir des entreprises et des représentants de fédérations professionnelles patronales ou syndicales » (AO-M 1A, p. 8). Claude Thomas expose sa philosophie de l'action du FNE dans un article publié avec Dominique Balmary (alors chargé de mission au cabinet de Joseph Fontanet) dans Droit social en décembre 1969 (C. Thomas, D. Balmary, 1969). Après son départ du travail, en 1971, Claude Thomas poursuivra sa carrière dans l'industrie, avant de revenir au ministère en entrant à l'IGAS.

(91) Yves Chaigneau est, en janvier 1976, chargé de mission au cabinet de Lionel Stoléru, secrétaire d'État chargé de la condition des travailleurs manuels, puis nommé, en octobre 1976, directeur de l'ANACT.

(92) Sur certains aspects des débuts de la nouvelle politique de l'emploi, $c f$. CAC 880594/1 (dossiers et notes annotées par Claude Thomas).

(93) Bien que n'étant pas directeur-adjoint, mais seulement adjoint au directeur général, Claude Thomas figure dans l'organigramme avant Olga Raffalovich et Pierre Demondion, respectivement directeurs-adjoints pour le Travail et pour l'Emploi, alors même qu'il n'est pas encore chef de service.

(94) Ce bureau est chargé des «aspects économiques de la politique du travail», ainsi que du «suivi des expériences en cours». la politique générale de l'emploi, confié en 1969 à Jacques Dupront (95).

Parallèlement, la direction générale se dote de nouveaux instruments de connaissance. Constituée dès 1949, la division statistique voit ses moyens s'accroître en 1964, avec l'arrivée d'un administrateur de l'INSEE supplémentaire, et sa première section prend en charge la fonction études, jusque-là assumée par la section des études générales. Comme le constatent, lors de leur enquête, J. LAUTMAN et J.C. Thenig (1966, p. 305), "l'efficacité de $S$ [NB: il s'agit du service de l'emploi], et plus largement de la direction, est considérée comme tributaire d'un nouveau type de savoir", d'un cadre cognitif qui se rapproche de celui utilisé par le Plan. Le cadre mental de référence, permettant de discuter avec des partenaires économiques au sein des commissions du Plan, est moins le code que la matrice de calcul de l'ajustement des ressources aux emplois. Le chiffre devient l'instrument cognitif essentiel dans une politique d'emploi (les taux d'emploi, les projections sectorielles...), et le moyen de mesure de ses instruments (les crédits d'aide à l'emploi) (96): il n'est pas seulement l'instrument d'appréhension de la situation à modifier (le marché de l'emploi), il sert aussi à évaluer les instruments de cette modification, qui sont de nature budgétaire (97). On touche là aux oppositions relevées par Lautman et Thœnig dans leur enquête: "Faire du chiffre n'est pas impliqué dans une conception de l'État arbitre et garant des lois » (LAUTMAN-Thenig, 1966, p. 312).

Toutefois, même dans ce contexte nouveau, demeure un principe de référence aux textes. La politique de l'emploi s'ancre elle aussi dans la règle exogène, sans que l'on éprouve toutefois le sentiment de la même potentialité d'effet, ce qui est ressenti comme "très désagréable» (98). On demeure néanmoins fier d'avoir participé à, ou suscité l'élaboration de certains textes: «qui ont été un progrès ", comme en matière d'indemnisation du chômage, où l'on s'est toujours "préoccupés de règles »: faut-il ou non faire payer des cotisations aux chômeurs? Et, lorsqu'un soir le ministre a voulu, à six heures, et pour six heures et demie,

(95) Tout comme ce dernier bureau avait pris la suite d'un «bureau d'études générales », lui-même héritier de la section des études générales de 1957, la section de la politique générale du travail est précédée, dès 1969, par le bureau d'études générales des conditions collectives de travail (alors placé sous l'autorité directe d'Olga Raffalovich, chef du service du travail).

(96) J. Lautman et J.-C. Thoenig montrent ainsi que l'on a cherché «à provoquer, à l'intérieur de X, plus d'attention pour la formulation quantitative» (1966, p. 298).

(97) Dans leur article consacré au FNE, Claude Thomas et Dominique Balmary écrivent que «l'accroissement des interventions du FNE apparaît à la lecture des crédits [qui lui sont] affectés »: 24 millions de francs en 1964, 63 en 1968 et 73 en 1969 (Thomas, Balmary, 1969, p. 577). Or «l'attitude des fonctionnaires n'est pas la même en face des textes et en face de l'argent» (AO-M 1B, p. 11).

(98) AO-M 11A, p. 33. 
fournir à un groupe parlementaire une proposition de loi sur le soutien aux chômeurs, le sous-directeur s'est réuni avec deux collaborateurs : "Tous les trois, on a pris le Code du travail - on avait quand même des idées :- [...], on a réussi à 6 heures 15 à avoir notre texte prêt $》(99)$.

Il y a au bout du texte un sentiment d'achèvement - on s'en souvient bien longtemps après: ( $J$ 'ai rédigé moi-même la circulaire que vous pouvez trouver quelque part dans le ministère: elle a une chemise bleue») (100): l'exécution est réalisation.

\section{L'exécution comme accomplissement}

De même que, selon M. Weber, le travail scientifique suppose de faire «des milliers d'opérations tout à fait triviales » (WEBER, 1919a, p. 83), une des qualités professionnelles de l'administrateur réside-t-elle dans une aptitude à «s'atteler résolument au traitement de sujets auxquels il ne porte aucun intérêt» (DALE, 1941, p. 84). Il a fallu peiner beaucoup: aller de manière sûre et rapide au fond des dossiers; assurer le secrétariat d'une commission d'étude sur les problèmes des retraites, ou ceux des conventions collectives pour les gens de maison - ou tout autre problème, surgi de l'imagination parfois inattendue du directeur de cabinet, mais pour lequel on ne ressent pas un attrait instinctif; participer de manière néanmoins attentive (il n'est pas d'usage de solliciter la répétition de ce qui a été dit) à des réunions aussi multiples que prolongées; encore, produire les «deux ou trois inévitables notes ». Et sans éprouver au bout du compte le sentiment gratifiant d'avoir fait quelque chose d'utile.

Il y a bien sûr les satisfactions anodines: des voyages, la rédaction de quelques articles, la participation à des jurys à l'ENA ou à l'Inspection du travail ou encore de menues activités extérieures, tels les enseignements à l'Inspection du travail - ils relèvent de l'ordre du devoir - , ou ceux dispensés à Sciences-Po, voire à l'ENA - ils sont source de plus grand orgueil. Mais ce sont là des à-côtés de la carrière, pas les vraies sources de cette réalisation existentielle, qui constitue la base de la motivation à s'accomplir dans les tâches mêmes métier.

Les décisions, écrit Simon à propos du phénomène central de l'«identification», ne sont pas faites par des «organisations», mais «par des individus se comportant comme des membres d'organisations» (Simon, 1965, p. 202). Si on l'envisage sous cet angle des rapports possibles entre les objectifs et valeurs personnels et ceux de l'organisation, l'accomplissement peut prendre plusieurs formes, qui se distribuent entre l'intérêt personnel dans le succès organisationnel d'une part, la réalisation organisationnelle de la personnalité intérieure

(99) AO-M 5A, p. 15.

(100) AO-M 6B, p. 6. d'autre part; une telle distinction se déploie aussi bien sur le versant juridique («les textes») que sur le versant extra-juridique de l'exécution.

L'identification personnelle de l'«homme administratif» aux réalisations de l'organisation est un premier niveau. En 1955, un élève de l'ENA en stage à la Compagnie des ateliers et forges de la Loire se voit proposer de venir à la réunion du comité d'établissement: il avait été l'un des rédacteurs de l'ordonnance de 1945. "J'ai été content de voir que ça existait vraiment! Parce qu'au moment où on a rédigé les textes, on se disait: "Est-ce que ça va vraiment exister?" (101). Sentiment convergent d'œuvre accomplie, lorsqu' on se rappelle avoir suscité, en 1963, le regroupement au sein du FNE des crédits destinés à l'emploi auparavant affectés au FDES, ou encore la création de nouveaux centres de la FPA (102). Dans le domaine de l'emploi encore, lorsque se font sentir les limites d'une action menée à l'aide du seul instrument budgétaire - le FNE en l'occurrence - : «Alors, on commençait à ressentir ça sans pouvoir bien le préciser, et on s'était dit: "Pour çà, il faut une autre administration, il faut d'autres ingrédients». Demeure la question de savoir qui est-ce «on»: «On, c'était... c'était surtout moi je dois dire». Alors, tout d'un coup, l'immodestie prend le dessus sur la servitude, et l'«on» passe sur l'autre versant. de l'identification simonienne, la réalisation organisationnelle accomplissant la personnalité intérieure, non seulement dans «le sentiment d'avoir fait quelque chose», mais de manière plus intime encore.

"Faire quelque chose» ne se fait pas sans résistance: quelqu'un a-t-il eu, parvenu à un poste plus élevé, fût-ce celui de sous-directeur, l'idée de proposer de réfléchir à une innovation? Le chef de bureau compétent lui a aussitôt fait valoir l'objection ne souffrant pas de réplique: "Monsieur, vous n'y songez pas! On ne peut changer cette règle; la Cour de Cassation [...]». Il aura fallu, dans la patience, conserver la pensée de la chose, tenir le tiroir «rempli», prêt à être ouvert, attendre l'instant propice pour pouvoir un jour, remontant prudemment au front, dire: "Monsieur le directeur, j'ai déjà réfléchi, j'ai une note, je vous l'apporte».

Tout en agissant comme membre de l'administration, la personne développe sa capacité créatrice singulière. Cela peut prendre corps par une paternité: le sentiment de l'origine ( $"$ Je me dis: "Quand même, l'origine [de ce terme de congé de formation], c'est une phrase que j'ai prononcée" " (103), ou celui, moins empreint de visibilité, de la transmission; cette sensation prend une dimension physique

(101) AO-M 7A, p. 16

(102) À la [sous-direction de la] Formation professionnelle, on m'a donné les crédits, si bien que j'ai pu faire ce que je voulais» (AO-M 7A, p. 5).

(103) AO-M 7B, p. 26 
s'étendant même au-delà de la stricte vie professionnelle: si c'est « moi » qui ai, " en tant que ministère », réalisé les investissements, alors ce «je», lorsqu'il circule en France et voit des panneaux «centre de FPA », peut se dire: "Ah oui au fait, c'est moi qui ai acheté ce terrain-là!»(104).

De la paternité, la puissance créatrice s'étend à l'invention. Avoir inventé un terme, une mesure, un dispositif. On se rappelle avec acuité des «travaux inventifs » que l'on a eu à faire. La redéfinition continue de la politique de l'emploi à partir de la fin de période, a été l'occasion de développer «cette capacité d'imagination e d'anticipation», perçue comme "partie intégrante du métier». Alors, la création personnelle s'incarne dans une tendance à la propriété, qui peut prendre la forme de la propriété intellectuelle, et il n'est pas insignifiant de souligner l'origine de l' "idée» (105). Nous touchons là à l'une des dimensions créatrices de l'exécution, éclairée de la remarque de R. Merton, soulignant que l'efficacité de la structure bureaucratique dépend d'une pénétration, parmi les employés, de sentiments personnels, qui «dépassent souvent le degré d'intensité techniquement nécessaire» (MERTON, 1940: p. 365).

Il s'agit néanmoins là de réalisations tournées vers l'extérieur, qui se doublent de la poursuite de satisfactions plus intimes, de l'ordre de la passion engageant les profondeurs de l'être. Passion intellectuelle pour le droit du travail ou intérêt «intellectuel» d'une action polyvalente découverte lors de l'arrivée à la DPM(106); exaltation transcendant le simple poste occupé dans la structure, résultant du sentiment de participer, en 1945-1950, à un élan collectif ou encore, en 1970-1975, à une mission nouvelle, "moment très fort du travail d'administration». Ou encore plaisir du chef du $9^{\mathrm{e}}$ bureau, étudiant en géographie avant de devenir rédacteur, chargé ensuite, à la sous-direction de la formation professionnelle, des programmes d'investissement, à regarder dans son bureau la carte de France, qu'il contribue à garnir, des centres de la FPA.

Associés à la singularité des personnalités, ces sentiments orientent des options comportementales différentes. L'amour de l'art de la règle est lié de manière consubstantielle aux formes mêmes de l'organisation. La pulsion d'inventivité institutionnelle (les réformes de 1945-1950, la démarche «de terrain» du FNE débutant, ou le «travail de transformation du ministère du Travail» évoqué avec enthousiasme par les pionniers de la Délégation à l'emploi, attirant les jeunes énarques des promotions 1965 à 1970) les déborde. Elle ouvre ainsi la voie aux «politiques organisationnelles» (SIMON,

(104) AO-M 7B, p. 15.

(105) AO-M 1A, p. 21.

(106) AO-M 10A, p. 14-15; 10B, p. 24.
1965, p. 147-149) et à leurs «charges de mission», qui mettent en cause la coordination par l'organisation stratifiée attribuant à chaque agent la charge exécutive définie par le poste, ainsi que la cohésion sous-tendue par le travail des «textes».

Si l'on s'est départi d'une attitude d'exécution comme «simple application», on passe alors de la réalisation de la personnalité organisationnelle, ou encore de la réalisation organisationnelle de la personnalité - deux versants de l'exécution comme accomplissement -, à de pures stratégies d'exécution mettant l'équilibre en péril. Les fonctionnaires de la période du cinquantenaire sont toutefois encore à l'abri de la politisation ultérieure, directement exprimée par la notion, maniée au pluriel, de «politiques». Dire qu'il y a «des» politiques d'emploi et, pourquoi pas - mais bien plus tard, avec la création du Bureau de la politique générale du travail - «des politiques» du travail, spécifiées sur des objets particuliers (tels la «condition des travailleurs manuels»(107)), c'est suggérer qu'il peut en exister plusieurs, non seulement successives, mais concomitantes et concurrentes, engageant des subjectivités disjointes.

L'existence d'identifications divergentes constitue l'un des principaux résultats de l'enquête menée par J. LAUTMAn et J.-C. Thenig (1966). Isolant (tout en les distinguant l'une de l'autre) les deux sousdirections des rapports économiques et sociaux du travail et du statut social du travailleur, du service de l'Emploi, ils relèvent un désaccord intense au sujet des fonctions sociétales du ministère. S'éloignant du plan de l'organisation, on dépasse alors l'analyse de la démarche opératoire (les fonctionnaires en travail, ou la «table» de R. GRÉGOIRE), pour envisager le plan institutionnel: le but externe de l'action, dans les liens établis avec l'environnement de l'organisation: les «dossiers» se trouvant sur la table. Qu'y a-t-il donc dans ces dossiers, quel est le travail des fonctionnaires?

\section{La fonction et le ministère}

Le 25 octobre 1956 au soir, dans le grand amphithéâtre de la Sorbonne, devant une assistance comprenant une élite du «social» venue des deux régimes républicains encadrant la guerre, le président du Conseil, Guy Mollet, soulignait que la législation sociale française était due à «l'action inlassable de milliers [...] de militants ouvriers». Et d'affirmer aussitôt que «ce n'est pas diminuer le mérite des militants que de rappeler l'appui ou

(107) $C f$. la création en $1976 \mathrm{du}$ secrétariat d'État confié à Lionel Stoléru, au cabinet de qui appartenait Yves Chaigneau, qui, douze ans plus tôt, avait été chargé de mission auprès de Jacques Chazelle à la DGTE. 
l'aide technique qu'ils ont si souvent rencontrés au ministère du Travail, c'est-à-dire à leur ministère » (108). Si « une agence publique doit, à la différence d'une entreprise privée, peser les décisions en termes de quelque système d'ensemble de valeurs publiques ou communes» (SImON, p. 69), alors les valeurs du Travail, toujours encadré par ses juristes sociaux, apparaissent, en 1956, bien éloignées de l'économie.

Néanmoins, dès 1945, le Travail ne s'était pas seulement engagé dans une œuvre législatrice nouvelle; il avait aussi été appelé à participer à la «bataille» de la production, cette invitation se trouvant prolongée après 1947 , alors que le $\mathrm{I}^{\text {er }}$ Plan abordait, dans un même mouvement, les questions du volume de la main-d'œuvre et celles de la productivité et de l'organisation du travail(109). Vingt ans plus tard, l'idée selon laquelle le ministère "doit agir dans les cadres économiques» (110), accompagnée de celle d'une «interdépendance de l'économique et du social»(111), s'est bel et bien implantée place de Fontenoy. Mais elle est, indiquent alors les chercheurs du groupe de sociologie des organisations, l'objet de désaccords prononcés, portant tant sur le fond (est-ce vraiment de cela qu'est chargé ce département?) que sur les moyens (problème des limites du département ministériel): le débat sur la relation de l'économique et du social ne se limite plus à l'opposition de deux ministres et de leurs départements (112): il s'est installé au sein du travail lui-même. En arrière-plan de ces dissensions, quelles visions de la société partagent ou non les fonctionnaires?

\section{Les charges du Travail}

La défense du monde ouvrier face aux abus, voilà ce qui, selon les fonctionnaires de la centrale - unis en cela à ceux des services extérieurs -, définit l'identité du Travail face aux administrations économiques. Non pas que les relations avec celles-ci soient inexistantes: 1'institution du SMIG par la loi du 11 février 1950 donne au ministère une compétence en matière de salaires-notamment

(108) Cinquantenaire du ministère du Travail, Texte des discours prononcés le 25 octobre 1956, Besançon, imprimerie Le Comtois, 20 décembre 1956, p. 19.

(109) Commissariat général du Plan, Deux ans d'exécution du plan de modernisation et d'équipement : 1947-1948, Paris, 1949, chapitre II : «Main-d'œuvre et productivité».

(110) C'est là l'un des jugements des agents de la Direction du travail sur les modes d'action souhaités, recueillis par J. LautMan et J.-C. Thoenig (1966: p. 300).

(111) Ibidem, p. 301

(112) Dès septembre 1944, Alexandre Parodi conteste auprès du ministre de l'Économie nationale, Pierre Mendès-France, le projet d'ordonnance voulu par ce dernier, tendant à ce que les projets «susceptibles d'avoir une répercussion sur la politique économique » soient soumis à son contreseing; Pierre MendèsFrance repousse les arguments de son collègue du travail. (CAC 770315/12, dossier signalé de la main d'Olga Raffalovich comme «correspondance de principe»). lors de l'extension des conventions collectives - , et amène ses représentants à participer aux instances intervenant dans la politique de fixation des salaires du secteur semi-public, au sein de la Commission interministérielle de coordination des salaires, rattachée au ministère des Finances. Les membres de la section d'études générales, chargée de ces affaires au sein de la Direction du travail, se montrent souvent en dissension avec ceux des finances (113). Que ce soit dans cette Commission de coordination, ou lors des réunions interministérielles précédant, en vue du relèvement du SMIG, la tenue de la Commission supérieure des conventions collectives, «la politique suivie était assez affligeante, pour un fonctionnaire du ministère du Travail»(114) - en fait, les taux proposés par les «économiques» dans la période postérieure à 1958 sont jugés insuffisants par les «travaillistes», qui déplorent une négligence à l'égard des bas salaires (115).

Ces débats-là ne correspondent en tout cas pas à une «sélection alternative» (SIMON, p. 66 ss.) au sein du ministère. Il en va différemment de l'introduction des préoccupations «industrielles». La formation professionnelle est appelée à articuler ses objectifs avec ceux de la transformation du paysage économique. Ceux-ci sont définis à la fois sectoriellement et territorialement: les lieux d'implantation des sections, que ce soit Tinteniac dans l'Ille-et-Vilaine, ou Egletons en Corrèze pour les travaux publics, représentent un des enjeux de la tutelle de l'ANIFRMO, puis de l'AFPA qui prend sa suite en 1966(116). Le travail devient un acteur de la politique d'aménagement du territoire (117) - qui, redéfinie dès 1955 (création du FDES), reçoit une impulsion déterminante par la création de la DATAR, en février 1963 (dix mois avant l'institution du FNE). Dans son ouvrage, publié en 1960, Pierre Demondion, alors sous-directeur de l'emploi, citant à plusieurs reprises les réflexions de géographes (J.F. Gravier (118)) et d'hommes politiques «aménageurs » (Eugène Claudius-Petit), souligne l' « intérêt d'une liaison permanente à maintenir entre les deux préoccupations» d'équilibre de l'emploi et d'aménagement du territoire (DEMONDION, 1960: p. 206). La première des quatre sections de la division de Coordination créée par Pierre Laurent, est chargée des affaires économiques et financières, compre-

(113) "Les Finances freinaient quand il s'agissait d'entreprises du secteur social, se montrant beaucoup plus généreuses avec les banques et les assurances; le Travail adoptait la position inverse. 》 (AO-M 6A, p. 4).

(114) AO-M 6A, p. 16.

(115) De telles dissensions se manifestent aussi dans d'autres domaines (à propos par exemple du versement de prestations familiales aux familles de travailleurs immigrés résidant à l'étranger). (AO-M 6A, p. 7)

(116) AO-M 7B, p. 6.

(117) Ibidem, p. 21.

(118) J.-F. Gravier, Paris et le désert français, Paris, Flammarion, 1947. 
nant les rapports avec le Plan et la politique régionale. Et, dès 1961, les orientations impulsées par ce directeur aboutissent progressivement à l'institution des dix échelons régionaux de l'Emploi (119), qui posent la région en cadre déconcentré de connaissance; ce choix limité en nombre - pour des raisons certes budgétaires (120) - , rompt avec l'approche traditionnelle, uniforme, de l'espace - préfigurant la détermination (à des fins opérationnelles) de quatre «zones d'emploi» en 1970 (121). La DATAR participe directement, à partir de 1964, aux travaux du Comité supérieur de l'emploi(122), aux réunions duquel est convié Jérôme Monod.

Sur le plan des préoccupations «verticales», Pierre Laurent encourage ses subordonnés à participer non seulement aux travaux de la Commission de la main-d'œuvre, mais aussi à ceux de la commission de la productivité du IVe Plan(123); dont est membre le chef du Bureau des relations du travail, Rustant. Déplacée d'une position plus subalterne vers le haut du nouvel organigramme centralisateur de la DGTMO, la sous-direction des relations professionnelles d'Olga Raffalovich prend en 1957 l'intitulé de «sous-direction des rapports économiques et sociaux de travail», en se voyant adjoindre une section des études générales, dont on a déjà évoqué le rôle en matière salariale (124). Le paysage des attributions s' " industrialise» davantage encore, avec la création en 1963 du bureau du FNE, rattaché non pas à la direction de la main-d'œuvre, mais au directeur général; sa fonction consiste à "traiter les problèmes de restructuration industrielle». Résumant cet état d'esprit, Jacques Chazelle, alors directeur général ayant succédé à Pierre Laurent, prenant la parole aux journées d'études consacrées au problème des fusions et concentrations, organisées par l'ESSEC en février 1966, souligne que c'est «de l'aptitude à répondre aux exigences d'une économie en mouvement que dépend le relèvement de niveau de vie des travailleurs» (125).

La constitution, en 1906, d'un département du travail se séparant de celui du commerce avait

(119) Le premier ERE est créé en 1961 à Nancy, Pierre Laurent s'appuyant notamment sur Gabriel Ducray, inspecteur du travail dans la 4 e circonscription: "Dans ce processus [de diversification de l'application de la réglementation nationale], le rôle des hommes est déterminant » (BOSMAN et alii 2006, p. 43).

(120) AO-M 7B, p. 24.

(121) Comité supérieur de l'emploi, 29 octobre 1970 (CAC 880594/1).

(122) Instituée par l'article 1 de la loi du 18 décembre 1963 relative au FNE, cette instance consultative se substitue à la Commission nationale de la main-d'œuvre.

(123) Un chapitre du rapport de cette commission est consacré aux «problèmes sociaux posés par la mise en œuvre d'une politique de productivité».

(124) L'ancienne sous-direction des salaires perd progressivement cette attribution, après être devenue la sous-direction de la réglementation, puis du statut social du travailleur.

(125) Essor 1966, ESSEC, «Fusions et concentrations, une nécessité économique?», p. 116. marqué l'institution d'un mouvement d'idées établissant, dans un domaine spécial, le primat du droit sur l'économie. Un demi-siècle plus tard, ses fonctionnaires - devenant acteurs de la politique de formation et d'utilisation «rationnelle» de la main-d'œuvre, impliqués dans la politique salariale, mobilisés dans les travaux du Plan, participant à ceux de la DATAR, alors installée rue La Boétie, aux côtés des représentants de l'industrie, retrouvant ces derniers, avec ceux des Finances, au sein des instances de l'OECE (puis de l'OCDE (126)) traitant de la politique de l'emploi -, ont-ils opéré une nouvelle «sélection» au sein de l'alternative entre le droit social et l'économie, tendant à réintégrer l'action de leur département au sein de la politique industrielle (127)?

En fait, ces options sont l'objet de conflits internes à la direction. Selon J. Lautman et J.-C. Thœnig, les agents de la sous-direction des Rapports économiques et sociaux du travail, alors dirigée par Olga Raffalovich, sont très divisés quant à la liaison entre le social et l'économique (ceux de la sous-direction $\mathrm{du}$ statut social du travailleur de Betty Piguet y sont aux trois quarts hostiles, et les quatre cinquièmes de ceux du service de l'Emploi, dont le chef est Claude Thomas, y sont favorables). Les premiers ne sontils pas les plus directement concernés par ce qui est perçu par une forte minorité (38\%) comme l'intrusion de nouvelles perspectives et de nouveaux outils (Lautman, Thenig, 1966, p. 301)?

Si en effet l'univers de l'entreprise - avec l'urgence parfois brutale de ses contraintes - auquel étaient jusque-là seuls confrontés les services extérieurs, devient une composante de l'horizon de l'administration centrale, cette «entreprise»-là n'est pas celle des inspecteurs, appréhendée par ces derniers dans les termes de la conformité aux règles ou de la déviance (128). Les entreprises avec lesquelles le service du FNE entre en relation sont des acteurs du développement économique; elles ont chacune une identité singulière, associée à un produit, une ville, un contexte: les chantiers de l'Atlantique et Saint-Nazaire, la Cotonnière d'Héricourt et le Territoire de Belfort, les aciéries de Pompey et la Lorraine...(129) Il s'agit d'allouer des fonds: les interlocuteurs de référence sont alors les patrons, non les travailleurs. Les premiers sont, dès 1964, les signataires avec le ministre du Travail des conventions d'allocation spéciale ou de promotion professionnelle. La convention entre l'État et les chan-

(126) Qui, succédant en septembre 1961 à l'Organisation européenne de coopération économique (OECE), élargit alors cette première organisation au-delà du cadre européen.

(127) AO-M 11A, p. 24-25.

(128) Cf. Lucot (2000), à propos de la direction départementale du travail et de la main-d'œuvre du Puy-de-Dôme, ch. I-3 : «Une activité prenant sa source dans le Code du travail».

(129) CAC 880594/1 à 4. Cf. dans l'article 1 les dossiers du Comité supérieur de l'emploi. 
tiers de l'Atlantique, examinée lors de la première réunion du Comité supérieur de l'emploi, le 28 avril 1964, est signée le 29 par Jean Pinczon, PDG des chantiers, et Jacques Chazelle (130), et c'est avec le président du directoire du groupe Wendel, Dherse, ou son secrétaire général, Loizillon, que sont, par la suite, discutés - courtoisement mais fermement - les désaccords éventuels sur les taux de remboursement par l'État des salaires des stagiaires (131). On peut aussi être interpellé, comme en 1971 par les dirigeants d'une petite PME de la construction électrique de Vittersbourg (Moselle), réclamant, après y avoir été incités de manière intempestive par le chef de l'Agence locale de l'emploi, le bénéfice des actions conjoncturelles en faveur des jeunes (132). C'est là une première source de dissension au sein d'une direction dont des bureaux entiers se consacrent à la protection des élus ouvriers face au pouvoir patronal.

Quant au Plan, il laisse plus d'un fonctionnaire sceptique. Car le «travail» dont il est question dans ses commissions n'est pas celui des fonctionnaires: le «travail», au Plan, c'est l'emploi! L'emploi, c'est-à-dire non pas un rapport social, mais «un truc quantitatif», une chose dénombrable: un facteur de la croissance. Avec une pointe d'exagération peut-être, on se rappelle certains sarcasmes venus de la sous-direction du Statut social du travailleur: "C'est de la prévision, Fourastié!»(133). «De la prévision...!»: et de présenter, «dans l'escalier de Lowendal», à un chargé de mission du Plan de passage, l'un des administrateurs de la sous-direction de la formation professionnelle: "C'est celui qui croit au Plan!»(134).

Césure entre attributions? Rien de certain: on l'a vu avec Lautman et Thœnig, la sous-direction la plus «économique», celle des rapports économiques et sociaux, est aussi la plus partagée. Entre générations? Pierre Fournier, l'un des tenants d'une action «industrielle» liée au territoire, appartient à la génération d'avant 1947, année d'arrivée du premier ancien élève de l'ENA au ministère. Entre

(130) CAC 880594/1.

(131) CAC 850092/20.

(132) CAC 880594/1, affaire société LEACH.

(133) Jean Fourastié, professeur d'économie au CNAM, est président de la Commission de la main-d'œuvre du Plan, depuis le Ier Plan (1947) jusqu'au Ve (1965). Il est l'un des animateurs du groupe de travail des prévisions de l'emploi, constitué en 1952 à la demande d'Alfred Rosier (directeur de la main-d'œuvre et vice-président de la commission de la maind'œuvre du Plan), qui réunit, au Commissariat général du Plan, les services du travail, de l'éducation nationale, de l'économie, l'INSEE, l'INED..., et remet un rapport à la Commission nationale de la main-d'œuvre siégeant chaque année au ministère du Travail (cf. Fourastié, 1956).

(134) AO-M 6A, p. 15-16. Il ressort par ailleurs de l'enquête de Lautman et Thœnig que $66 \%$ des fonctionnaires interrogés portaient d'une manière ou d'une autre un jugement défavorable sur le Plan, $29 \%$ s'y déclarant «favorables sans plus» (p. 310). juristes et économistes? Non : Pierre Laurent, maître des requêtes et promoteur de la nouvelle politique de l'emploi(135), tout comme les inspecteurs du travail, ancrés quant à eux dans la réalité industrielle, sont des praticiens du droit.

La mise en cause de l'«unité d'action» du travail, thème de l'étude du groupe de sociologie des organisations, repose sur des conceptions différenciées de la relation avec l'environnement: «Une analyse de sociologie organisationnelle [...] doit être complétée par une étude des rapports avec l'extérieur»; de fait, «le mode de découpage du réel que pratique X ne coïncide pas avec celui du Plan» (Lautman, Thenig, 1966, p. 313; 310). On retrouve là les orientations cognitives différenciées liées à la «bifurcation de la voie sociale», déjà envisagée. Les «questions sociales» auxquelles sont formées les nouveaux administrateurs correspondent à une conception du social découplée de la notion de condition ouvrière, traitant d'un même mouvement la protection des droits des travailleurs et la protection socialisée de tous face aux risques de l'existence humaine, dans le contexte d'une politique économique française globale (136). Une telle imbrication semble manifeste lorsque, lors de la toute première réunion du Comité supérieur de l'emploi, le 28 avril 1964, Gilbert Grandval, présidant à Fontenoy la grande table en fer-à-cheval de la salle 300 , se trouve - selon une symétrie parfaite - entouré à sa droite de Jacques Chazelle, puis de l'Aménagement du territoire, de la Promotion sociale et enfin des Finances; et, à sa gauche, de Claude Thomas, suivi du Plan, de l'Agriculture et de l'Industrie (patrons et syndicalistes se trouvant aux extrémités, les premiers côté finances et les seconds côté industrie - entre cette dernière et les syndicats, face au patronat, l'UNEDIC, etc.) (137).

Le grand ministère confiéà Jean-Marcel Jeanneney constitue un pas de côté par rapport à une évolution qui tendait à réintégrer les champs de l'industrie et du Travail "On a été englobés dans l'ensemble affaires sociales; on se rapprochait de la santé,, avec l'action sociale, les handicapés, et on a perdu le contact à ce moment-là avec les administrations à vocation économique: Plan, DATAR...»(138). Ce pas se trouve accentué lorsque, dès 1967, s'installe durablement un déséquilibre de l'emploi - que ne suffit pas à enrayer le volontarisme affiché lors de la préparation du $\mathrm{VI}^{\mathrm{e}}$ Plan-, accentué par les

(135) Pierre Laurent, «Les aspects nouveaux de la politique de l'emploi » (conférence prononcée devant le Centre d'études supérieures de banque le 20 juin 1963, reproduite dans la Revue française du travail, avril-juin 1963, p. 9-22).

(136) $C f$. A. DE Lattre (1966): il s'agit du cours dispensé par cet éminent inspecteur des finances, directeur des finances extérieures, à l'IEP de Paris.

(137) CAC 880594/1, Comité supérieur de l'emploi, 1964 : plan de salle préparatoire à la réunion.

(138) AO-M 7B, p. 22 
«concentrations», premier pas de «restructurations» qui dorénavant ne cessent plus(139). Tout en "prenant conscience, avec le patronat, des conséquences économiques du Marché commun», le ministère des travailleurs allait devenir le ministère des personnes privées d'emploi(140), ce qui déplaçait les options de la sélection des alternatives, opposant non plus tant le droit à l'économie que le travail au « social», dont la cible à venir serait moins le travailleur menacé par l'arbitraire de la division sociale du travail, que le client potentiel du travail social.

\section{Les limites du département}

Dans l'exposition organisée, à l'occasion du cinquantenaire, par les soins de Pierre Fournier, dans les locaux de la bibliothèque de la place de Fontenoy, du 23 octobre au 10 novembre 1956, une grande part était faite aux documents historico-juridiques, du décret du 25 février 1848 sur le droit au travail, à l'ordonnance du 22 février 1945 sur les comités d'entreprise. De fait, «la législation» fut l'héroïne honorée, dans sa longue allocution de la soirée commémorative du 25 octobre, par Jean Minjoz, secrétaire d'État(141), donnant à voir le Travail comme un ministère des textes. L'effectivité du texte - décret, circulaire ou instruction -, ne dépend pas toutefois de ses auteurs, mais de ceux qui le reçoivent, parties visées ou fonctionnaires chargés de la mise en œuvre et du contrôle.

On peut, tout en la transformant en interrogation, paraphraser la remarque célèbre de P. Weil, selon laquelle «l'existence même d'un droit administratif relève en quelque sorte du miracle» (WeIL, 1964, p. 5): compte tenu de l'écart existant entre les fins externes et les moyens internes, l'existence même d'une administration effective du travail relève-telle du «miracle»?

Non seulement la section d'inspection de Saintes ou de Roanne apparaît lointaine à qui a vue surl'École militaire: ses membres sont, de surcroît, séparés de ceux des bureaux centraux par une rigide barrière statutaire jouant dans les deux sens: ni pénétration d'un inspecteur dans les bureaux, ni intrusion d'un administrateur de la Centrale à l'«extérieur» (142). Que dire en outre des bureaux départementaux de la main-d'œuvre, que l'on peut trouver, encore en

(139) Selon les calculs effectués à l'époque par le ministère, les DENS (données CVS) connaissent une croissance continue

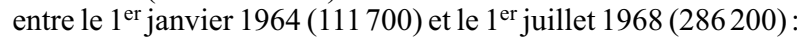
réunion du CSE du 25 septembre 1968, exposé de Dominique Balmary sur la situation de l'emploi (CAC 880594/1).

(140) AO-M 5B, p. 3.

(141) Textes des discours, op. cit., p. 7.

(142) AO-M 7A, p. 10; 6B, p. 14.
1967, situés dans des ruelles (143) ou à l'arrière de cités administratives, derrière les guichets desquels attendent des agents peu qualifiés et démotivés, parfois occupés à faire du tricot(144)? Quant à la politique industrielle: les fonctionnaires de l'administration centrale ne vont pas dans les entreprises; ceux qui, «sur le terrain», visitent celles-ci, ne vont pas en fonction en centrale (145), et, si l'on assure le suivi hebdomadaire des conflits sociaux, pour l'information du gouvernement, avec un système de fiches (146), c'est "un système très traditionnel, faites par l'inspection du travail - mais absolument inefficace, fait avec beaucoup de retard». Certes, le ministère est "pauvre», ses ressources organisationnelles propres sont limitées: "Il est resté longtemps, du point de vue de ses effectifs, un petit ministère » (147), apparaissant aux élèves sortant de l'ENA comme en charge de "questions de second rang ». Les corps d'inspection générale et de contrôle général sont, jusqu'à la création de l'IGAS en 1966, éclatés et rabattus sur une vocation «technique». Un autre élément de faiblesse au sein de l'organisation générale de l'État est le caractère variable du périmètre administratif du Travail, oscillant entre les deux pôles d'un rattachement commun avec la Sécurité sociale, et de l'identité propre - sans parler de son abaissement au rang de simple secrétariat d'État(148). Et, si c'est l'hôtel abritant le ministre qui donne son nom à l'accord destiné à trouver une issue au mouvement de mai 1968, la présence de Jean-Marcel Jeanneney lors des journées de discussion des 25, 26 et 27 mai à Grenelle est celle d'un hôte davantage que d'un acteur: c'est le Premier ministre, Georges Pompidou, qui mène la négociation(149).

Ce sentiment de faiblesse est ressenti lorsqu'en réunion interministérielle, on se trouve face aux "visages de bronze» des membres de la Direction du budget, ou confronté à la simple méfiance des représentants de l'Industrie, ou encore que l'on s'aperçoit être, dans le processus, auréolé de rigueur de la planification, en position latérale: lors des réunions de la Commission supérieure des conven-

(143) «À Montreuil, le bureau de main-d'œuvre est installé dans un immeuble délabré, dont les murs lézardés ont été tapissés d'affiches par le personnel pour éviter les courants d'air» (DGTE, Rapport pour une rénovation des services de l'emploi, juin 1964, p. 20).

(144) AO-M 2C, p. 5.

(145) AO-M 7A, p. 10

(146) CAC 810323/1 à 11 .

(147) $\mathrm{Au} 1^{\text {er }}$ mai 1964, les effectifs théoriques des services extérieurs s'élevaient (toutes catégories confondues) à 5407 agents (contre 5436 au $1^{\mathrm{er}}$ janvier 1948 - et 31763 , en 1958 , pour l'Office fédéral allemand pour le placement). Sur ces 5407 agents, les trois quarts étaient affectés aux services de maind'œuvre. Source: Rapport pour une rénovation des services de l'emploi, op. cit., p. 16 et annexe IV bis).

(148) Au moment du cinquantenaire, Jean Minjoz se trouve ainsi placé sous l'autorité d'Albert Gazier.

(149) CAC 860561/2, dossier «Grenelle». 
tions collectives, "le ministère du Travail jouait un rôle d'organisateur de réunions et de mise en forme juridique, [on] rédigeait le procès-verbal», mais «les vraies décisions économiques étaient prises à la direction générale des Prix» (150). Le ministère a une ambition institutionnelle, mais elle est fragile: sa réalisation repose sur la conformation des chefs d'entreprise à la loi, garantie par le pouvoir d'un corps sur lequel ses propres fonctionnaires n'ont pas d'emprise (151), et dont l'indépendance est étayée par les obligations découlant de la convention $\mathrm{n}^{\circ} 81$ de l'OIT relative à l'indépendance de l'inspection (152); ce phénomène est structurel(153). Et pourtant continue de s'effectuer, et de progresser, l'encadrement du travail. Derrière le «miracle», que se passe-t-il?

Le Travail n'est pas un ensemble isolé au sein de l'univers, en expansion, du social. De 1946 jusqu'à 1967, sont créés des organes extérieurs, qui pour certains renforcent la capillarité de son action au sein de l'organisation sociale, et pour d'autres lui permettent de mieux l'étendre. La création des directions départementales en 1946, sans mettre en cause la césure statutaire, introduit un nouvel élément dans la relation disjointe entre la centrale et les services extérieurs.

L'échelon régional est consolidé, et le directeur général, Pierre Laurent, tient des réunions régionales dans les grandes inspections divisionnaires (154). Dans le cadre de l'application de la loi du 18 décembre 1963, des directeurs régionaux commencent à demander une délégation de pouvoir : pourquoi faire «se déplacer à Paris [...] les responsables des entreprises » concernées, alors qu'il suffirait que soient «mises à la disposition des directions [déconcentrées] un certain nombre d'exemplaires de conventions type?»(155)

Les divisionnaires - puis les directeurs régionaux -, sont réunis une fois par trimestre place de Fontenoy (156): "On venait faire le point sur un texte qui allait sortir [...], quelquefois on leur demandait de réagir aux questions qu'on leur avait posées ». Ces exercices sont, certes, souvent considérés comme "artificiels»: style trop général des exposés des directions centrales, caractère insuffisant de la préparation locale - d'autant que les responsables territoriaux ne mettent pas tous un

(150) AO-M 7A, p. 7-8.

(151) Sur la perception réciproque de la centrale et de l'inspection, $c f$. AO-M 6B, p. 16-22; 10B, p. 23.

(152) OIT, convention sur l'inspection du travail, 1947, article 6: «Le statut et les conditions de service des fonctionnaires de l'inspection [...] les rendent indépendants de tout changement de gouvernement et de toute influence extérieure indue». (153) AO-M 6A, p. 19.

(154) AO-M 8, p. 9.

(155) Lettre du 20 janvier 1967 du directeur régional d'Aquitaine au ministre des Affaires sociales (CAC 880594/1).

(156) AO-M 6B, p. 15. même empressement à faire «redescendre» l'information recueillie au niveau national(157). Il demeure qu'ils permettent une meilleure interconnaissance, allant au-delà des seuls appels téléphoniques ou échanges de bordereaux avec les services départementaux, et, partant, une amorce de coordination. Ces contacts sont bienvenus, alors que les directions départementales sont confrontées, en 1967, à la perte d'une partie de leurs attributions, transférées à la toute nouvelle Agence pour l'emploi (ANPE): "Ça a été une levée formidable d'oppositions de la part de la majorité des directeurs départementaux 》 (158). Les directeurs départementaux se perçoivent en effet comme dépossédés d'une partie, jugée importante, de leurs missions, et les contrôleurs du travail voient s'échapper l'accès au corps des chefs de centre des services départementaux de la main-d'œuvre - encore qu'une partie des cadres nouveaux soit recrutée au sein des cadres propres des services extérieurs déconcentrés.

L'établissement de l'ANPE était, toutefois, seulement l'une des deux branches de l'alternative qui s'ouvrait, alors que - dans le contexte de l'expérience de la Bourse de l'emploi pour les rapatriés et de la nouvelle politique de l'emploi - Jacques Chazelle avait constitué, à la DGTE, un groupe composé de trois responsables de services extérieurs et de trois responsables centraux (159), chargé de proposer une rénovation des structures et des méthodes des services de l'emploi. Dans le rapport remis au ministre en juin 1964, était préconisée la création d'un échelon interrégional, le renforcement de la coordination au niveau des circonscriptions d'action régionale, cadres du «développement économique régional», et la réorganisation des services départementaux, avec la création d'un «réseau de sections locales de l'emploi», parallèles aux sections d'inspection du travail (160). Cette voie - définie par le secrétaire d'État chargé de l'emploi, Jacques Chirac, comme le «renforcement des services existants», alors que, le 22 septembre 1967, rue de Tilsitt, il présente devant le Comité supérieur de l'emploi la toute nouvelle

(157) «Et quand on demandait aux inspecteurs $d u$ travail: "Quels échos avez-vous eus des instructions qui ont été données au directeur régional à la dernière réunion?", [beaucoup] disaient: "Aucun!"”. (Ibidem).

(158) AO-M 2C, p. 5. Lorsque Jean-Marcel Jeanneney, accompagné de son secrétaire d'État Jacques Chirac, vint confirmer la création de l'ANPE lors du banquet de clôture du congrès du SNITMO réuni en juin 1967 à Orléans, "cela jeta un froid sur l'assistance» (AO-M 2C, p. 8).

(159) Parmi lesquels la directrice de l'administration générale et du personnel, Jeanne Laumond, ainsi que son adjoint, Claude Delaunay.

(160) Rapport pour une rénovation des services de l'emploi, op. cit., p. 23-41. En 1964 et 1965, Jacques Chazelle défend ce projet tant devant la Commission interministérielle de la réforme administrative que devant la Commission de la main-d'œuvre $\mathrm{du} \mathrm{V}^{\mathrm{e}}$ Plan, laquelle «approuve sans réserve» les propositions issues de la DGTE, Rapport général de la Commission de la main-d'œuvre, Paris, La Documentation française, mars 1966, p. 270). 
Agence issue des ordonnances du 13 juillet-, ne fut pas retenue: le gouvernement lui avait préféré, à la suite du «rapport Ortoli» (161), et pour reprendre les mots de Jacques Chirac, la création d'un « organisme para-administratif nouveau»(162). Entretemps (en 1966), Gilbert Grandval puis Jacques Chazelle avaient quitté le ministère, et avec eux - pour un temps du moins - une certaine puissance d'initiative institutionnelle prenant source depuis le travail (163). Lorsque la mission conversions du Plan réunit, le $1^{\mathrm{er}}$ mars 1967, autour des responsables du Commissariat, les représentants des administrations concernées par la réorganisation des services de l'Emploi, Jacques Legrand, le nouveau directeur de la DGTE, était seulement un acteur parmi d'autres (164).

Voulue alors que l'on est en pleine période d'exécution du Ve Plan et que les «experts de la rue de Martignac» voient se profiler le chiffre alors fatidique du demi-million de chômeurs (165), la constitution de l'ANPE n'est pas isolable du mouvement plus général de création d'organes décentralisés de la politique sociale, qu'ils soient de nature opérationnelle, comme l'ONI, l'ANIFRMO (devenue

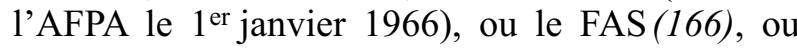
encore voués à la recherche, tels l'INED ou le CEE. Ces organes sont autant de moyens subsidiaires, de nature à susciter des conflits «inter-organisationnels » (167), mais aussi à augmenter le pouvoir d'action - et donc à repousser les limites du « département»-: car on aura maintes fois l'occasion de dire, suivant l'un des mécanismes psychologi-

(161) F.-X. ORTOLI, Rapport sur les conséquences sociales de l'évolution des structures de l'économie, Paris, Commissariat général du Plan, avril 1967 (doc. multigr.). Ce rapport (réalisé au service des affaires sociales du Plan, dont le chef était alors Jacques Delors) fait suite aux travaux de la mission conversions constituée dans le cadre du SAS, de la fin 1966 au printemps 1967; elle réunit notamment, outre François-Xavier Ortoli, le commissaire, Jean Ripert, président de la Commission emploi du VI ${ }^{\mathrm{e}}$ Plan, Jacques Delors, Marie-Thérèse Join-Lambert, chargée de mission au SAS. La mission prend langue avec les organisations syndicales et patronales et l'UNEDIC, elle se déplace en Allemagne (CAC 920452/3).

(162) CAC 880594/1, réunion du Comité supérieur de l'emploi, 22 septembre 1967. Cf. aussi les déclarations de Jacques Chirac devant la commission de la main-d'œuvre du Plan, le 17 octobre 1967 (CAC 920452/2).

(163) C'est d'ailleurs, on l'a vu, au Plan, que Jacques Chazelle trouve, de 1966 à 1968, une position temporaire après son départ de la DGTE.

(164) En mars 1967, le SAS propose un "programme triennal de développement des services de l'emploi», dans lequel est suggéré, alternativement au renforcement des services propres du travail, la «création d'un office» (CAC 920452/3).

(165) Alors que le chiffre de 500000 chômeurs mesure le «clignotant emploi» du Ve Plan, on dénombre, en 1968, en moyenne annuelle, 451000 chômeurs (au sens du recensement): Commission de l'emploi du Plan, «État de l'exécution du Ve Plan dans le domaine de l'emploi», 30 septembre 1969: CAC 920452/2).

(166) Sur le FAS, $c f$. V. VIET 1998, p. 328 ss.

(167) Ainsi les problèmes posés par le projet de transfert des psychotechniciens de l'AFPA à l'ANPE. ques d'identification pointés par Simon (p. 209210) (168), que l' « on a» l'AFPA, et qu' " en passant à la DPM» "on y trouve» le FAS ou l'INED. Ce n'est pas seulement que ces associations ou établissements offrent des débouchés naturels pour la «mobilité» des administrateurs civils du ministère: le sous-directeur du petit ministère est le tuteur de fait de grands organismes, qui emploient des milliers de personnes (169).

La tutelle est un contrôle, qui ne consiste pas en une emprise sur la vie courante des organes concernés (170) - le sous-directeur ne s'embarrasse pas des rapports compliqués avec les «trois cents psychos » de l'AFPA - , mais en une relation de pouvoir avec leurs dirigeants, à l'indépendance limitée ne serait-ce que par les crédits budgétaires et les choix stratégiques. Si ces derniers ne sont pas non plus le fait du sous-directeur, qui on le sait n'est qu'un «ministre inversé», c'est néanmoins lui qui, au contact direct avec son «envers »- ou plutôt le cabinet, «lieu-tenant» de ce dernier, peut, de manière stratégique, suggérer au téléphone ce que "le ministre a dit», ou faire la confidence secrète de ce qui s'est échappé du Conseil des ministres, pour ne rien dire de "ce qu'exige» l'Élysée. De manière moins nimbée de halo, et comme on a bien des problèmes de routine à régler en commun - les investissements... - " on y va» (171), avec "son» chef de bureau en charge de l'organisme(172). Les relations sont souvent cordiales, parfois plus faciles avec les partenaires qu'avec le contrôleur d'État, représentant les finances, inséparable vis-àvis de l'administrateur de gestion, mais non convié quant à lui au (bon) repas - où l'on demeure entre «sociaux»-, qui précède la réunion du conseil d'administration.

$\mathrm{Si}$, pour revenir à la formule de $\mathrm{P}$. Weil, il est un «miracle» dans l'administration, c'est celui par lequel - loin du modèle bureaucratique -, quotidiennement et dans ses limites propres, la mise en œuvre de la politique du département repose sur autre chose que le commandement: d'une part, à l'égard des services extérieurs, sur le trait d'union que constitue le texte; d'autre part, vis-à-vis des organismes sous tutelle, sur un lien de confiance;

(168) Il parle à ce sujet de «transfer of private-management psychology» (p. 209-210).

(169) Au $1^{\text {er }}$ janvier 1969, l'ANPE compte un peu plus de 1000 salariés; ce chiffre passe à 3400 au $1^{\text {er }}$ octobre 1970 , et à 9000 à la fin de 1974 (l'AFPA employant environ 8000 personnes) - contre 4400 alors pour les services extérieurs du travail et de l'emploi (la création de l'ANPE ayant entraîné une baisse d'effectifs de ces derniers par rapport à 1964). Cf. CAC 880594/1, CSE du 29 octobre 1970; et Comptes de l'emploi, données physico-financières 1973-1980, Paris, La Documentation française, 1982, p. 146-148).

(170) Sur le phénomène de la tutelle, $c f$. AO-M 7B, p. 12-17.

(171) AO-M 7B, p. 16-17.

(172) Sur les rapports entre les responsables du ministère et ceux de l'ANIFRMO à l'époque de la transformation de celleci en AFPA $c f$. DÄNZER-KANTOF (1999), p. 116-121. 
enfin, par rapport aux acteurs sociaux, sur l'aptitude à réagir positivement aux incitations normatives ou budgétaires - et, dans tous les cas, sur la disposition d'acteurs avec lesquels on n'est pas en relation d'autorité directe.

\section{La société des fonctionnaires}

Revenons aux images de R. Grégoire : le fonctionnaire est assis sur son "fauteuil », face à la "table» sur laquelle s'entassent les "dossiers» à traiter: chemises et leurs sous-chemises, dont le volet du dessus est replié en deux dans le sens de la hauteur, pour identifier du premier coup d'œil la nature du courrier à traiter ou de la note à reprendre. Dossier juridique ou financier, social ou bien économique? Le vrai problème n'est peut-être pas là : il existe une appréhension du monde, une sociologie spontanée gouvernant la posture mentale qui aboutit à élaborer le dossier. Si le «social» est une transformation de relations sociales ou de problèmes sociaux en règles formelles et en dispositifs, présupposant une évaluation de la société, quelle est en 1956 la «société des fonctionnaires»? À quel groupe s'identifie-t-on, comment conçoit-on l'action sociale, dans quel contexte sociétal se situe-t-on?

La «vie sociale» est lointaine; la vision que l'on en a se nourrit souvent de menus faits de l'expérience quotidienne: l'amie veuve tracassée par les finances; la perplexité devant la déclaration, exigée par le fisc, de la dizaine de francs perçue au titre de la qualité, en tant que directeur général du travail, d'administrateur des Houillères; les difficultés auxquelles fait face, pour l'embauche de ses apprentis, l'artisan que l'on a rencontré lors de promenades à bicyclette en vacances: si elles étaient levées à grande échelle, la situation de l'emploi pourrait peut-être s'améliorer. C'est avec le même «sens commun»(173) - commun à la communauté des citoyens - , issu de l'expérience sensible, que sont appréhendées les expériences externes tirées des postes occupés : ainsi pour saisir le problème des "malheureux travailleurs» des chantiers de l'Atlantique, à qui il faudrait permettre de ne pas être seulement capables, "à 50 ans, de coller un rivet sur une coque». On oscille entre ce sens commun de monsieur Tout le monde et le cadre cognitif rationnel du cadre administratif supérieur: il est malheureux que les usines ferment, mais les concentrations sont nécessaires.

À qui se réfère-t-on dans la brochure que publie, en octobre 1956, le ministère à l'occasion de son

(173) «Vous savez, moi, en matière administrative, je dis que la France crève [sic] sous le nombre de textes et de bouts de textes qui s'ajoutent les uns aux autres. Les feuilles d'impôt! C'est un casse-tête chinois même pour un vieux fonctionnaire. » (AO-M 11B, p. 17). cinquantenaire (174), et dont la rédaction, due à Pierre Fournier(175), a été attentivement relue par Olga Raffalovich(176)? D'abord à des manifestants ouvriers (177) (et aux hommes politiques qui ont «repris» leur idée), puis aux syndicats (178). Bien plus loin(179), l'inspection du travail: elle a «derrière elle un long passé de services rendus à la cause du progrès social». Du ministère proprement dit, de ses fonctionnaires, il n'est pas question: ils sont comme les simples serviteurs d'un «progrès » dont le ressort est ailleurs: dans le syndicalisme et le «mouvement social», dirigé contre le patronat, et dont est partie prenante le «droit ouvrier». De ce mouvement, ils sont porteurs de la mémoire (180). L'entreprise est un simple lieu d'application de la politique du travail.

Elle n'est pas pour autant absente: on a élaboré l'ordonnance de 1945 sur les comités d'entreprise, dont l'application est suivie en 1956 par le $4^{\mathrm{e}}$ bureau: mais c'est une entreprise-institution, assurant la représentation du personnel, celle qu'au même moment théorise P. Durand dans une intervention qui devait longtemps retenir l'attention (DuRAND, 1947). En fin de période, la perspective se déplace : l'entreprise de Claude Thomas, le chef du service du FNE, n'est plus vue d'abord comme un domaine étranger dans lequel il faut faire avancer les positions de travailleurs menacés dans leurs droits (181). Elle est aussi un acteur dont la coopération est indispensable à la mise en œuvre de la politique de l'emploi (182) (la décision d'embauche est une prérogative de son chef): l'adversaire du travailleur est un client du marché du travail, marché sur lequel le ministère, via l'ANPE, est devenu un organisateur de l'offre (183).

(174) Cinquantenaire du ministère du Travail, Besançon, Imprimerie coopérative, 1956.

(175) «Cinquantenaire 56», archives CHATEFP, op. cit.

(176) CAC 860561/2, dossier «Exposition du cinquantenaire», constitué par Olga Raffalovich.

(177) Cinquantenaire du ministère du Travail, op. cit., p. 7.

(178) Le premier chapitre est consacré au «rôle du syndicalisme dans la vie économique et sociale du pays» (p. 13-15); puis viennent « les employeurs et travailleurs dans le cadre des conventions collectives» (p. 16-19).

(179) Ibidem, p. 53.

(180) «Nous étions la mémoire du bureau [chargé des représentants du personnel]; une mémoire juridique, mais aussi la mémoire des luttes qu'il avait fallu mener pour arriver [là]». (AO-M 9A, p. 23-24).

(181) AO-M 12, p. 8.

(182) La convention du 29 avril 1964 entre les chantiers de l'Atlantique et le FNE est d'ailleurs intitulée «convention de coopération»".

(183) Dans une note rédigée au Plan peu après la création de l'ANPE, Jacques Delors, commentant la nouvelle organisation administrative (dépendante des services du travail), écrit à propos de ces derniers: "Peut-on à la fois exercer une magistrature allant jusqu'à la répression, et établir des rapports de confiance avec les chefs d'entreprise pour obtenir d'eux, par leur libre consentement, leur coopération en matière [...] de rassemblement des offres d'emploi? » («L'État et les problèmes de l'emploi», novembre 1967, p. 31, CAC 920452/3). 
Davantage que d'une évolution toutefois, il s'agit là d'un balancement d'orientation entre les différents pôles d'un même système de relations sociales, dont l'administration du Travail est, dans un contexte d'économie dirigée, un acteur de premier rang. La préférence pour les travailleurs se réalise dans le cadre formel de l'exercice du droit, et ne signifie pas un engagement militant. S'il existe un préjugé favorable pour les salariés, il ne convient pas pour autant de "[dire] qu'il y avait un préjugé défavorable à l'égard des employeurs»(184). C'est là l'orientation «centrale» tenue par Olga Raffalovich (qui peut entretenir d'ailleurs des relations cordiales avec certains milieux patronaux)(185): concilier les «impératifs dictés par le redressement de l'économie» et «les revendications légitimes des travailleurs», combiner la «latitude de s'accorder» des «parties contractantes» et «l'initiative nécessaire et souvent plus efficace du législateur» (186).

Concluant sa thèse soutenue en 1937, Renée Petit, futur chef du bureau des conventions collectives, définissait ces conventions comme «un instrument de collaboration entre le patronat et le salariat, [...] un instrument de paix sociale. Elle ne peut $[. .$.$] être utilisée que pour pacifier, [et pas$ comme] un instrument de lutte sociale. [...] $« \mathrm{Ce}$ nouveau droit ajoutait-elle, a pour corollaire [...] une morale collective» (PETIT, 1937, p. 195-196). Se dessine ici une orientation quasi-«durkheimienne», tendant vers la diminution des tensions sociales, au moyen d' «une amélioration de la situation économique des salariés, par la revitalisation de leur représentation syndicale, par [leur] expression plus libre dans l'entreprise». Une telle «philosophie» de l'administrateur central (187) est en miroir de son activité au sein des grandes commissions encadrant le système national de relations professionnelles : à la Commission supérieure des conventions collectives, ou à la Commission nationale de conciliation, on rencontre, en la personne des représentants syndicaux et patronaux - Henri Krasucki pour la CGT, Jean Neidinger, secrétaire général de la commission sociale du CNPF, ou encore Jean

(184) AO-M 6B, p. 22.

(185) Comme en témoigne le courrier que lui adresse, le 26 février 1946, un responsable de l'UIMM. à propos des demandes ouvrières d'augmentation salariale. (CAC 770315/12, dossier «Problème des salaires»).

(186) O. RafFalovich, «La conclusion des conventions collectives du travail», Revue française du travail, janvier-février 1949, p. 3-18.

(187) Commentant, dans la chronique «ministère du Travail» qu'il assure alors régulièrement dans La Revue administrative, l'ordonnance du 7 janvier 1959 sur l'intéressement des travailleurs à l'entreprise et ses suites réglementaires, Pierre DEMONDION souhaite que ces textes nouveaux contribuent à créer un «climat» comparable à l' 'état d'esprit» promu par le mouvement coopératif. (La Revue administrative, janvierfévrier 1960, p. 60-61). Pierre Demondion s'était intéressé par des études à l'organisation corporatiste, pendant la Seconde Guerre mondiale, alors qu'il était sous-chef de bureau à la Direction du travail. et Renée Nousbaum, figures de proue de l'Union des industries textiles -, des acteurs influents du système de relations professionnelles. Mais les relations entre membres de l'élite «sociale» demeurent dans le registre de la courtoisie de réunion: si, d'aventure, l'on accepte une - voire deux ! - invitations à déjeuner de la part du CNPF, on s'avise alors de marquer que le partage de la table ne saurait se poursuivre plus avant, sauf si venait une invitation symétrique, en provenance des syndicats - il faut "tenir la balance égale»- ... mais ces derniers se gardent de la lancer.

Un ministère est un ensemble de charges; c'est aussi, on le sait, un "département». Un ministère peut également consister en «bons offices». Le fait que le «ministère inversé» soit ainsi «entremise» et non prise de parti, relie les pratiques du sousdirecteur à Fontenoy à celles du directeur territorial réunissant, de manière répétée, dans la Loire, la section départementale de la Commission régionale de conciliation, commission paritaire présidée par le directeur départemental, sur convocation - demandée par ce dernier-du préfet. Il y a là "des gens des deux bords, [...], jouant totalement leur rôle», c'est-à-dire "s 'impliquant personnellement pour aboutir au règlement du conflit». Mais cette ultime étape ne peut se passer de l'entremise du directeur départemental: il s'agit de permettre aux parties d'exposer leurs principes - ne sont-ils pas «venus pour ça»? -, et, après un déjeuner, voulu court et léger, longuement suivi de leurs concertations et allées et venues internes (188), de les «laisser sur leur faim» dans la soirée avant le rite de la conclusion dans les heures qui précèdent l'aube.

Entre l'action du directeur départemental, dont les locaux sont régulièrement envahis, mais qui «connaît bien les syndicats de son département», et parvient à chaque fois, sans faire appel au préfet, à obtenir l'évacuation ("il ne faut jamais les autoriser à passer la première nuit»), et celle du directeur général à qui, "à peine installé [en 1957], le ministre [...] téléphone [après de] graves troubles aux chantiers de Saint-Nazaire ", il existe une continuité de préoccupation: "organiser la conciliation sociale» (LEGENDRE, 1992, p. 334). À l'un comme à l'autre de répondre, depuis leur poste et en administrateurs, à la question politique: "Qu'est-ce qu'on va faire des ouvriers, comment les reconvertir? »

Parce qu'il est le département entretenant les contacts les plus denses avec les syndicalistes, le ministère tient ainsi une fonction d'intermédiaire habituel

(188) «On négociait quand on avait mis les deux parties dans des pièces séparées, et où [on] - moi, et les membres les plus actifs de la Commission-commençait à aller des uns aux autres, essayant de faire le point. Et à partir de ce moment, je disais qu'on ne sortait plus avant [d'être] arrivés à la conclusion.» (AO-M 2C, p. 14). 
entre les univers politique et «social». Pourtant, les fonctionnaires savent que, pour les problèmes importants, les interlocuteurs privilégiés se rencontrent ailleurs, en la personne des conseillers sociaux du Premier ministre et du président de la République: on retrouve là les limites du département, marquées de manière encore accentuée lorsque, à partir de 1969, l'ancien chef du SAS du Plan, devenu conseiller social du Premier ministre, Jacques Delors, systématise la «politique contractuelle».

On touche ici au problème «simonien» de l'«adéquation», revers de ce que nous avons appelé l'«accomplissement»: l'«identification» se traduit par un échec de la confrontation des valeurs et des coûts lors de la prise de décision - d'où la création d'un programme administratif comme mode de réalisation de la personnalité organisationnelle. Là où le manager d'entreprise évalue l'action en termes d' «efficience», l' «homme administratif» se demande seulement quel est le degré auquel les buts ont été atteints : la mesure proposée s'est-elle avérée adéquate par rapport au problème posé (189)?

Ainsi, quand le «libre cours» de sa carrière l'a conduit au sein d'une grande entreprise du secteur privé, un haut fonctionnaire du secteur de l'emploi n'a pu manquer de faire des constats. Qu'a-t-il appris de saillant (190)? "C'est d'abord la question de l'argent ». Non pas la frénésie d'une quête d'opportunités lucratives. Mais un certain «soin»: un franc est toujours un franc, mais un franc dans l'entreprise "pèse beaucoup plus lourd» qu'un franc budgétaire (191). Le commis d'État n'est ni moins honnête, ni plus négligent, que le baron d'entreprise; "mais on ne le sait pas, ce que ça pèse, ce que c'est lourd à gagner, [l'argent]». Inversement, les fonctionnaires partagent la même croyance: en l'«efficace-propre» de la réglementation: on «améliore» le problème par la création de règles ou de systèmes (192): le problème demeurait «encore à régler»; il ne fallait pas que l'agriculture ou les transports le fissent à notre place (193). «On pourrait

(189) L'efficience est le degré auquel les buts ont été atteints relativement aux ressources disponibles (SIMON, 1965, p. 212). (190) Éprouvé à propos du montage interne d'une société de conversion, qui requérait de trouver trois postes, et de disposer de quelques moyens logistiques (bureaux, téléphones...).

(191) «Ce qui pour moi, dans l'administration, était un petit crédit, 500000 francs par exemple - par rapport aux milliards!-, c'était gros dans l'entreprise, même pour une entreprise qui faisait 85 milliards de chiffre d'affaires! Ca m'a pris beaucoup plus de temps que dans l'administration. 》 (AOM 1B, p. 20)

(192) Comme celui de l'indemnisation du chômage. Cf. AOM 8,p. 14.

(193) "Une réunion dans le bureau du directeur, avec un sous-directeur; il y avait une bataille, parce qu'un autre ministère voulait faire. - "Mais il faut les laisser faire, puisqu'on ne fait rien [...]" "Oui" [dit le sous-directeur - une éminente juriste], "on ne fait rien, mais on pourrait faire!" 》 (AO-M 3B, p. 10). faire» : les problèmes n'auront de cesse qu'on n'aie «fait»-sans se laisser «absorber» (194).

Mais ni la société ni le social ne sont des catégories ou des réalités singulièrement françaises: l'industrialisation porte au général. Le travail s'inscrit dans le champ appréhendé par l'OIT; à partir de 1947 , le $7^{\mathrm{e}}$ bureau suit l'application des conventions internationales, et, la même année, Olga Raffalovich participe aux conférences de l'OIT, dont elle devient membre gouvernemental, dès 1951, rapporteur de la Commission des relations professionnelles (195). Si toutefois l'environnement du travail est mondial, une partie de plus en plus conséquente de son action se place dans un périmètre plus restreint: à la DGTMO, on perçoit rapidement les conséquences industrielles de la CECA, dont la haute autorité intervient en matière d'amélioration des conditions de vie et de travail (196). On est amené à participer à des travaux de sous-commission du comité de politique économique à moyen terme du Marché commun, consacrés aux politiques salariales, ou à des réunions de négociation précédant l'adoption du règlement de libre-circulation des travailleurs ou, plus tard, la directive 77/187 relative à la cession d'entreprise, qui allait modifier l'article L.-122-12. On se rend également à des réunions informelles de hauts fonctionnaires des pays de la Communauté, suggérées par les ministres: "Nos collaborateurs pourraient se voir». Parfois les ministres «aiment à être accompagnés de leurs fonctionnaires résidant en France» (197): par rapport à ceux de la délégation permanente française, "on [est] plus de la table du ministre», qu'on a "vu la veille ou l'avantveille», alors que le "Bruxellois» possède seulement l'information donnée par le ministère.

Entre ces deux périmètres, large et plus restreint, sont les ordres de relation déterminés par l'état des relations internationales, marqué par la "guerre froide » : si les visites en Allemagne fédérale - pays de référence en matière de formation professionnelle et d'organisation du marché du travail-, sont fréquentes, en revanche les Affaires étrangères s'opposent à une mission en RDA, dont l'intention était de s'informer sur les systèmes d'insertion professionnelle des jeunes à la sortie des écoles (198). Cela n'empêche pas un autre voyage, en Sibérie celui-là, où l'on découvre les systèmes d'incitation salariale à la mobilité mises en place par le gouvernement soviétique. De manière paral-

(194) AO-M 8, p. 13.

(195) CAC 860561/3.

(196) Haute Autorité du charbon et de l'acier, Europe 1958: cinq ans de Marché commun pour le charbon et pour l'acier, Luxembourg, 1958, p. 27-30.

(197) AO-M 11B, p. 23-24.

(198) AO-M 11B, p. 22. 
lèle, on participe aux réunions du comité social de l'Union de l'Europe occidentale (199).

L'horizon s'est ouvert. Mais sous quel angle le considère-t-on? C'est la position française sur le droit d'organisation et la négociation collective qu'Olga Raffalovich entend, en 1947, faire prévaloir, face aux Britanniques, à Genève (200). Bien plus tard, on constate avec regret, lors d'un jury à l'ENA, que, parmi les élèves à qui on avait proposé de se déplacer pour traiter les questions posées, «aucun n'était allé faire un tour à l'étranger, même à Bruxelles » (201). Surtout, les échanges internationaux ne sont pas l'occasion d'une confrontation réfléchie entre réglementations, sauf pour vérifier avec plaisir que «la France est plus respectueuse que n'importe lequel autre État» (202). Qu'on l'entende comme le cadre concret de l'ENA, ou bien comme manière de faire partagée, l'école française d'administration demeure, alors, «nationale».

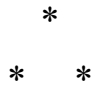

Les voyages à Bruxelles n'étaient toutefois "pas seulement fastidieux", ou source de désenchantement: "Il y avait des gens sympathiques, ça vous changeait de l'atmosphère du bureau et de la hiérarchie de votre maison ». Nous entraînant hors de l'Hexagone, ils nous reconduisent au tableau, peint par H.E. Dale, de la daily life du civil servant britannique (DALE, 1941 : ch. II).
La journée s'achève, aux alentours de Whitehall. Qu'est-il arrivé ce jour? Rien que de très ordinaire : cet après-midi, comme une ou deux fois par semaine, il aura fallu participer à une commission, accueillir un visiteur, être présent à une réunion. Peut-être le sujet traité ne présentait-il aucun intérêt, et on a pu n'être qu'un observateur détaché. "Mais ce genre de bonheur est rare.» Il est plus probable qu'on aura dû présider - ou être un protagoniste, une fois de plus "engagé dans l'affrontement quotidien ", dans un rôle ressenti aujourd'hui comme lassant. De ce genre-là de réunion, qui a pu durer jusqu'à deux heures et demie de temps, voilà donc le servant de retour à son bureau, éprouvant le sentiment de n'être plus aussi jeune qu'il le fut (Dale, 1941, p. 31).

À Paris comme à Londres, au long cours de la carrière et d'un «fauteuil» à l'autre, on n'a pas tardé à être désabusé, devant sa «table», par de petites choses (la découverte de dix «faux chômeurs » à la suite d'une visite-surprise à la direction départementale de Perpignan) (203), avant de devenir sceptique devant des «dossiers» en impliquant de plus grandes (des rapports d'inspection générale passés à la trappe politique) (204). Si l'on est conscient d'avoir, parfois, eu une influence ce sentiment demeure modeste: "Il faut avoir suffisamment d'humilité pour ne pas croire qu'on a réformé la France». Pour le serviteur, la gloire est une anomalie.
(199) Organisation issue du traité de Bruxelles du 17 mars 1948 instituant, face au système du pacte de Varsovie, une coopération économique et sociale entre États européens; son Comité social coopère avec le BIT.

(200) CAC 860561/3.

(201) AO-M 6B, p. 9.

(202) «Nous partions soit avec des instructions bien précises, soit sans instructions, mais dans les deux cas, c'était: "Veillez à ce qu'on change aussi peu que possible la réglementation nationale". [Aussi] on n'avait pas l'impression de bâtir l'Europe de demain » (AO-M 6B, p. 11-12).
(203) AO-M 11B, p. 21

(204) AO-M 6A, p. 26. 


\section{Bibliographie}

Annales ESC (1989), «Histoire et sciences sociales: un tournant critique», $\mathrm{n}^{\circ} 6$ ( $\mathrm{n}^{\circ}$ spécial).

Béthouart B. (2006). Le ministère du Travail et de la Sécurité sociale de la Libération au début de la $V^{e}$ République, Presses universitaires de Rennes.

Bosman F., Chetcuti C., Eck J.-F. (2006), «L’État local dans les relations du travail: le Nord-Pas-de-Calais (1841-1981), in Chatriot A., Join-Lambert O., Viet V., Les politiques du travail (1906-2006), Presses universitaires de Rennes, p. 29-44.

Crozier M. (1955), Petits fonctionnaires au travail, Paris, CNRS.

Crozier M. (1963), Le phénomène bureaucratique, Paris, Le Seuil.

Dale H.E. (1941), The Higher Civil Service of Great Britain, Oxford University Press.

Demondion P. (1960), Les problèmes de l'emploi, Paris, Berger-Levrault.

Descamps F. (1991), «Les archives orales du comité pour l'histoire économique et financière ou la fabrication d'une source», Éudes et documents du comité pour l'histoire économique et financière, III, pp 511-538.

Descamps F., éd., (2006), Les sources orales et l'histoire: récits de vie, entretiens, témoignages oraux, Rosny-sousBois, Bréal.

DuRAND P. (1947), «Rapport sur la notion juridique de l'entreprise", in Travaux de l'Association HenriCapitant pour la culture juridique française, t. III, Paris, Dalloz, p. 45-60.

DuRAND P. (1953) La politique contemporaine de Sécurité sociale, Paris, Dalloz (rééd. 2005).

FouRASTIÉ $\mathbf{J}$ (1956), «Recherches relatives à la prévision de l'emploi», Population, avril-juin, p. 261-270).

FrIDENSON P. (1989), "Les organisations, un nouvel objet», Annales ESC, nº 6: p. 1461-1477.

GrÉGOIRE R. (1954), La fonction publique, Paris, Armand Colin (rééd. Dalloz 2005).

Hennis W. (1996), La problématique de Max Weber, Paris, PUF (première éd. 1987).

Lattre A. de (1966), Politique économique de la France depuis 1945, Paris, Sirey.

Lautman J., Thenig J.-C. (1966), «Conflits internes et unité d'action: le cas d'une administration centrale», Sociologie du travail, $\mathrm{n}^{\circ}$ 3, p. 296-316.

Legendre P. (1992), Trésor historique de l'État en France: l'administration classique, Paris, Fayard (édition revue et augmentée de la première édition, 1968).

Lucot L. (2000), La direction départementale du travailet de la main-d'œuvre du Puy-de-Dôme entre 1945 et 1975, mémoire de maîtrise, département d'histoire, ClermontFerrand, université Blaise Pascal, (doc. multigr.).

March J., Olsen J. eds (1976), Ambiguity and Choice in Organizations, Oslo, Stockholm, Scandinavian University Press.

March J., Simon H. (1989), "Les organisations: problèmes psychosociologiques", Paris, Dunod (première édition 1958).

Mény Y., Thenig J.-C. (1989), Politiques publiques, Paris, PUF.

Merton R.K. (1940), "Bureaucratic Structure and Personality”, Social Forces, XVII, p. 560-568, repris dans Merton R.K (1952), p. 361-371.

Merton R.K. ed. (1952), Bureaucracy, New York (NY), The Free Press.

MOUSNIER R. (1974), Les institutions de la France sous la monarchie absolue, tome I, Paris, PUF.

Petit R. (1937), Les conventions collectives de travail: notions historiques et commentaire théorique et pratique de la loi du 24 juin 1936, Paris, Jouve.

Pochard M. (1976), L'emploi et ses problèmes, Paris, PUF.

Schrameck O. (2006), Dans l'ombre de la République: les cabinets ministériels, Paris, Dalloz.

Simon H.A. (1965), Administrative Behavior: A Study of Decision-Making Processes in Administrative Organization, New York (NY), The Free Press (première édition 1945).

Siwek-Pouydesseau J. (1969), Le personnel de direction des ministères, Paris, Armand Colin.

Sociologie du TRAVAIL (1966/3), «L'administration face aux problèmes de changement», ( ${ }^{\circ}$ spécial). $C f$. aussi dans ce numéro l'article de M. Crozier, «Crise et renouveau dans l'administration française», p. 227-248.

Thomas C., Balmary D. (1969), «Le Fonds national de l'emploi», Droit social, no 12, décembre, p. 575-585.

VIET V. (1998), La France immigrée: construction d'une politique, 1994-1997, Paris, Fayard.

Weber M. (1913), Essai sur quelques catégories de la sociologie compréhensive, Tübingen, Mohr, 1973.

Weber M. (1919a), «Le métier et la vocation de savant», trad. in Le savant et le politique, Paris, UGE.

Weber M. (1919b), «Le métier et la vocation d'homme politique», trad. in Le savant et le politique, Paris, UGE.

Weber M (1922), Économie et société, deuxième partie, chapitres III-II-5, trad., Paris, Plon, 1971.

WeIL P. (1964), Le droit administratif, Paris, PUF. 


\section{Sources imprimées}

Bottin administratif, Paris, Didot-Bottin (éditions annuelles 1943 à 1976).

BrÉAud P. (1970), «Qu'est-ce que la RCB?», in $R C B$, Bulletin interministériel pour la rationalisation des choix budgétaires, septembre 1970, p. 11-17.

Chetcuti C. (2000), «Structure du ministère du Travail depuis 1939», Études et documents pour l'histoire de l'administration du travail, Cahiers du CHATEFP, $\mathrm{n}^{\circ} 2$ 3, p. 199-262.

Cinquantenaire du ministère du Travail (1956), Besançon, Imprimerie coopérative, 1956.

Cinquantenaire du ministère du Travail (1956), texte des discours prononcés le 25 octobre 1956, Besançon: imprimerie Le Comtois, 20 décembre 1956.

Commissariat GÉNÉral du Plan (1949), Deux ans d'exécution du plan de modernisation et d'équipement: 1947-1948, Paris.

Commissariat génÉral du Plan, Ve Plan (1966), Rapport général de la Commission de la main-d'œuvre, Paris, La Documentation française.

Comptes de l'emploi, données physico-financières 19731980, Paris, La Documentation française, 1982.

DÄNZER-KANTOF B. (1999), Former pour l'emploi, l'AFPA: 50 ans de formation professionnelle des adultes, Montreuil, AFPA.

Direction générale du Travail et de l'Emploi (1964), Rapport pour une rénovation des services de l'emploi, Paris, ministère du Travail, juin 1964 (doc. multigr.).

ENA, Épreuves; Statistiques des concours, Paris, Imprimerie nationale (recueil annuel).

Dupront J. (1967), «Les mouvements de salaires conventionnels de 1960 à 1966», Revue française des affaires sociales, juillet-septembre 1967, p. 97-122.

Fournier P. (1966), «Problèmes actuels de la formation professionnelle des adultes », Revue française du travail, $\mathrm{n}^{\circ} 3$, juillet-septembre 1966, p. 9-36.

Fournier P. (2006), Quarante ans place de Fontenoy, Presses universitaires de Rennes.

Gorecki M. (1957), «Pour une réforme de la législation du travail: faut-il instituer, en France, une assurance chômage?», La revue administrative, juillet-août 1957 , p. $358-365$.

Haute-Autorité du charbon et de l'acier, Europe 1958: cinq ans de Marché commun pour le charbon et pour l'acier, Luxembourg, 1958, p. 27-30.

LARoque P. (éd.) (1955, 1963), Les institutions sociales de la France, Paris, La Documentation française.
LAURENT P. (1961), «Les problèmes sociaux posés par la conversion des entreprises $»$, Revue française du travail, $\mathrm{n}^{\mathrm{o}} 2$, avril-juin 1961, p. 3-22.

LAurent P. (1963), «Les aspects nouveaux de la politique de l'emploi», Revue française du travail, avril-juin 1963, p. 9-22.

MARquié F. (2000), «La reconversion des chantiers et arsenaux de la marine (1946-1953)», Revue historique des armées, $\mathrm{n}^{\circ} 220$, p. 112-127.

Organisation internationale du Travail (1947), convention sur l'inspection du travail.

Raffalovich O. (1949), «La conclusion des conventions collectives du travail», Revue française du travail, janvier-février 1949, p. 3-18.

Sfez L. (1986), «Comment maîtriser les technologies de l'esprit?», Le Monde, 23 avril 1986.

\section{Sources d'archives écrites et orales}

Centre des archives contemporaines (Fontainebleau)

$770315 / 12$ à 14: dossiers constitués par Olga Raffalovich.

810323/1 : conflits collectifs du travail.

$850092 / 20:$ FNE.

860561/1 à 3 : dossiers constitués par Olga Raffalovich.

$880594 / 1$ à 4 : FNE ( $N B$ : il s'agit d'un versement contenant les dossiers de Claude Thomas).

920452/1 à 4: service des affaires sociales du Commissariat général du Plan.

760180/10 à 16: Direction de l'action sociale (NB: fonds Sibileau, sous-directeur de la réadaptation et de la vieillesse, condisciple de promotion de Gabriel Oheix à l'ENA).

Archives d'histoire contemporaine (Centre d'histoire de Sciences-Po)

Archives du Club Jean-Moulin: 1 CJM 2; 5 CJM 1; 6 CJM 1 (activités et interventions de Michel Crozier et Jean-Daniel Reynaud).

Archives du CHATEFP, Versement Pierre Fournier, dossier « cinquantenaire $56 »$.

\section{Autres archives}

Archives non répertoriées de la Direction de l'action sociale.

Archives orales du CHATEFP, Fonds P. Maclouf: articles $1 \mathrm{~A}$ à 13 .

Maclouf P. (2006), «Histoire orale et histoire des institutions ", in CHATEFP, archives orales du ministère du Travail, notice introductive (Fonds P. Maclouf). 


\section{Revue \\ internationale \\ du Travail}

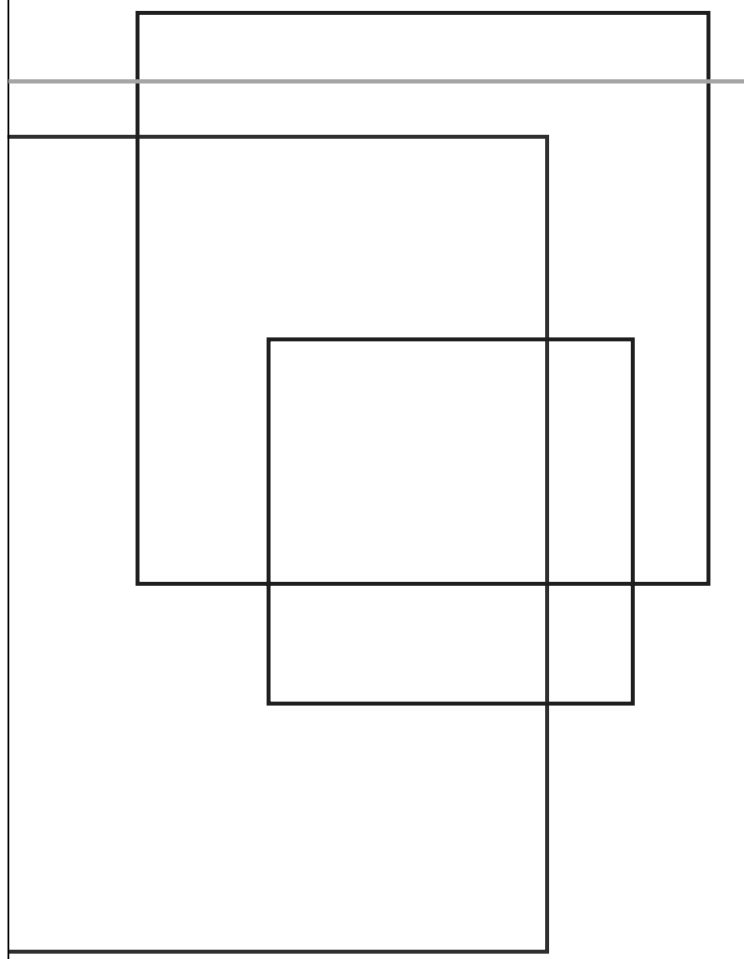

www.ilo.org/revue

\section{Vol. 146 (2007), no 1-2}

Sur l'application du droit du travailet de l'emploi au-delà du contrat de travail M. FREEDLAND

Au-delà des codes de conduite commerciaux: l'organisation du travail et les normes du travail chez les fournisseurs de Nike R. LOCKE, T. KOCHAN, M. ROMIS et F. QIN

La répartition des salaires dans les pays de l'OCDE

\section{A. B. ATKINSON}

Externalisation, délocalisations et mesure de la productivité dans l'industrie aux Etats-Unis

S. HOUSEMAN

Economie informelle, insécurité et cohésion sociale en Amérique latine

V. E. TOKMAN

Notes, documents et commmuniqués

\section{Livres}

Abonnement à l'édition imprimée et accès à l'édition électronique (2007):

Institutions: 1 an: 240 fr. suisses; 155 euros; 195 \$EU

Particuliers: 1 an: 120 fr. suisses; 80 euros; 95 \$EU

Edition électronique seulement: un an: 135 fr. suisses; 85 euros; 110 \$EU

Publications du BIT, Bureau international du Travail, CH-1211 Genève 22, Suisse

Fax: (41-22) 799.69.38; Tél.: 799.78.28; E-mail: pubvente@ilo.org 